\title{
Low-Temperature Nitrogen Doping of Nanocrystalline Graphene Films with Tunable Pyridinic-N and Pyrrolic-N by Cold-Wall Plasma- Assisted Chemical Vapor Deposition
}

Nur Hamizah Zainal Ariffin, Muhammad Aniq Shazni Mohammad Haniff,* Mohd Ismahadi Syono, Mohd Ambri Mohamed, Azrul Azlan Hamzah, and Abdul Manaf Hashim*

Cite This: ACS Omega 2021, 6, 23710-23722

Read Online

ABSTRACT: We report a viable method to produce nanocrystalline graphene films on polycrystalline nickel $(\mathrm{Ni})$ with enhanced $\mathrm{N}$ doping at low temperatures by a cold-wall plasma-assisted chemical vapor deposition (CVD) method. The growth of nanocrystalline graphene films was carried out in a benzene/ammonia/argon $\left(\mathrm{C}_{6} \mathrm{H}_{6} / \mathrm{NH}_{3} / \mathrm{Ar}\right)$ system, in which the temperature of the substrate heated by Joule heating can be further lowered to $100{ }^{\circ} \mathrm{C}$ to achieve a low sheet resistance of $3.3 \mathrm{k} \Omega \mathrm{sq}^{-1}$ at a high optical transmittance of $97.2 \%$. The morphological, structural, and electrical properties and the chemical compositions of the obtained $\mathrm{N}$-doped nanocrystalline graphene films can be tailored by
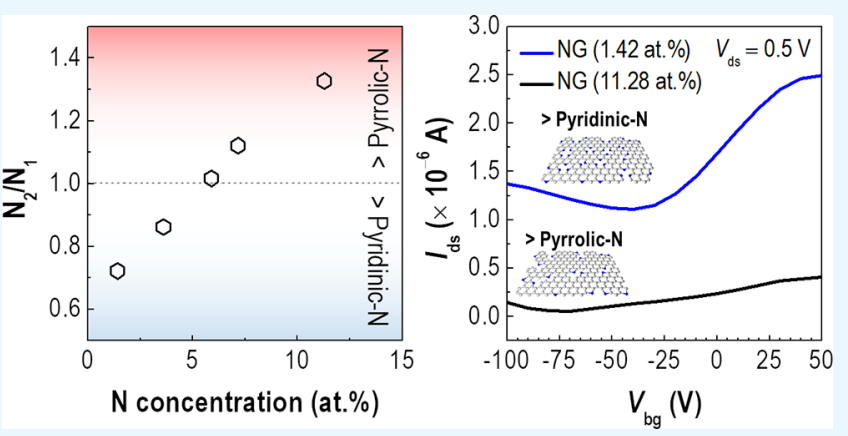
controlling the growth parameters. An increase in the concentration of atomic $\mathrm{N}$ from 1.42 to 11.28 atomic percent (at.\%) is expected due to the synergetic effects of a high $\mathrm{NH}_{3} / \mathrm{Ar}$ ratio and plasma power. The possible growth mechanism of nanocrystalline graphene films is also discussed to understand the basic chemical reactions that occur at such low temperatures with the presence of plasma as well as the formation of pyridinic- $\mathrm{N}$ - and pyrrolic- $\mathrm{N}$ dominated nanocrystalline graphene. The realization of nanocrystalline graphene films with enhanced $\mathrm{N}$ doping at $100{ }^{\circ} \mathrm{C}$ may open great potential in developing future transparent nanodevices.

\section{INTRODUCTION}

Graphene, a two-dimensional material with $\mathrm{sp}^{2}$-hybridized carbon atoms arranged in a honeycomb lattice, has gained great attention from researchers for its unique properties in terms of optical, electronic, mechanical, and chemical properties. ${ }^{1}$ In view of these, it has been considered as one of the promising materials for widespread applications such as fieldeffect transistors, ${ }^{2}$ transparent conductive films, ${ }^{3,4}$ solar cells, ${ }^{5}$ photodetectors, $^{6-8}$ sensors, $^{9-11}$ and so forth. However, the utilization of graphene in most nanoelectronic applications is restricted due to its gapless states in pristine form. ${ }^{12,13}$ To exploit possible modifications or tailoring its properties, it is, therefore, necessary to control the charge carrier concentration by tuning the Fermi level $\left(E_{\mathrm{F}}\right)$. The method applied for band gap tuning in graphene is through doping such as surface transfer doping, substitutional doping, or chemical doping. ${ }^{14}$

Substitutional doping of heteroatoms such as boron (B) or nitrogen $(\mathrm{N})$ in the graphene is one of the most investigated methods since it is inherently stable due to the covalent bond linkage of the dopant into the graphene lattice. ${ }^{15}$ Among $\mathrm{B}$ and $\mathrm{N}$ atoms, $\mathrm{N}$ substitution in graphene is most preferable due to its excellent properties such as comparable atomic size and possession of five valence electrons. ${ }^{16}$ Particularly, N-doped graphene has three common bonding configurations known as
pyrrolic-N, pyridinic-N, and graphitic-N. Pyridinic-N refers to a $\mathrm{N}$ atom that substitutes within the two carbon (C) atoms at the edges or defects of graphene and contributes one $p$ electron to the $\pi$ system, while pyrrolic- $N$ refers to a $\mathrm{N}$ atom that substitutes into the five-membered ring and contributes two $p$ electrons to the $\pi$ system. However, graphitic-N refers to a $\mathrm{N}$ atom that substitutes for $\mathrm{C}$ atoms in the hexagonal rings. ${ }^{17}$ For instance, these bonding configurations have a significant effect on the charge distribution of the carbon network and may work as activation sites on the graphene surface, i.e., pyridinic- $\mathrm{N}$ is believed to be associated with oxygen reduction reaction (ORR) activities due to the availability of a single lone pair of the electron, which is considered as an active catalytic center. $^{18}$

Direct synthesis through the chemical vapor deposition (CVD) method is widely used to produce $\mathrm{N}$-doped graphene

Received: March 22, 2021

Published: September 10, 2021 

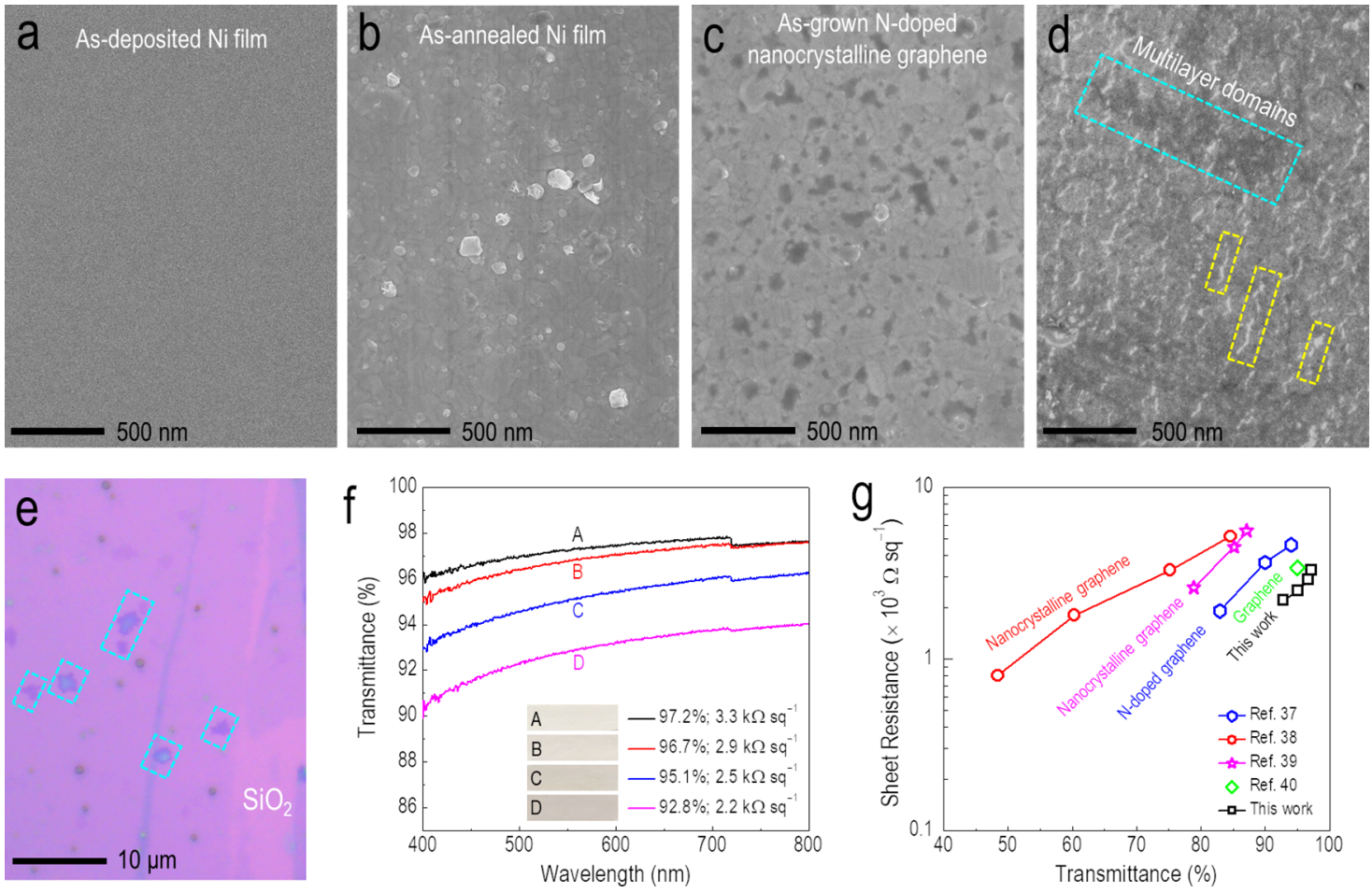

Figure 1. Morphological and electrical properties of N-doped nanocrystalline graphene films. FESEM images of (a) as-deposited Ni film, (b) asannealed $\mathrm{Ni}$ film, (c) as-grown $\mathrm{N}$-doped nanocrystalline graphene films on the $\mathrm{Ni}$ film, and (d) as-transferred $\mathrm{N}$-doped nanocrystalline graphene films on the $\mathrm{SiO}_{2} / \mathrm{Si}(100)$ substrate $\mathrm{The} \mathrm{SiO}_{2}$ surface can be seen in the yellow box. (e) Optical micrograph of N-doped nanocrystalline graphene films on $\mathrm{SiO}_{2} / \mathrm{Si}(100)$ substrate showing several spots of multilayer domains underneath the top layers in the cyan box. $\mathrm{The}^{\mathrm{SiO}} \mathrm{O}_{2}$ surface is represented by light color contrast. (f) Optical transmittance of $\mathrm{N}$-doped nanocrystalline graphene films at different growth conditions. The insets show the photographs of $\mathrm{N}$-doped nanocrystalline graphene samples transferred onto the quartz substrate on white paper background. (g) Comparison of the sheet resistance and optical transmittance obtained in the present work and other existing works in the literature.

because of its economic efficiency, scalability, and acceptance by the semiconductor industry. A typical CVD route to produce $\mathrm{N}$-doped graphene has been reported using various carbon precursors such as methane, acetylene, or pyridine at high temperatures in the range of $800-1050{ }^{\circ} \mathrm{C} .{ }^{19-22}$ In most cases, high-temperature processes mostly result in dominant graphitic-N configuration over the large-area graphene. ${ }^{19,23}$ Great deal of effort is always required in limiting the hightemperature processes due to severe physical damage to the substrates or devices, especially during the integration of graphene onto the nanoelectronics platform. Therefore, lowtemperature growth of graphene is highly desirable as it is a more economical and convenient process on any lowtemperature substrate. To achieve this, $\mathrm{Ni}$ and alloy metals have been reported as suitable catalysts for further reduction of the growth temperature while maintaining the same graphene quality as compared to that obtained by high-temperature processes. $^{24,25}$

On the other hand, one promising way to realize the lowtemperature growth of $\mathrm{N}$-doped graphene is employing plasma-assisted CVD. ${ }^{26-30}$ It is believed that the plasma does not only further lower the temperature for the growth of $\mathrm{N}$-doped graphene but also can provide substantial free radicals for highly efficient $\mathrm{N}$ substitution in the direct growth of nanographene films. Meanwhile, several groups have demonstrated that the reduction of the growth temperature can be achieved using polyhalogenated aromatic compound ${ }^{26}$ or heteroatoms containing carbon sources such as pyridine ${ }^{31,32}$ that possess a similar structure to benzene for producing highquality graphene. ${ }^{33} \mathrm{~A}$ few studies have also been demonstrated that the growth temperature of $\mathrm{N}$-doped graphene can be lowered to $435{ }^{\circ} \mathrm{C}$, in which the $\mathrm{N}$ atoms are mainly incorporated in the pyridinic-N form. ${ }^{28,29}$ Meanwhile, at a much lower temperature of $300{ }^{\circ} \mathrm{C}$, a recent study of $\mathrm{N}$-doped graphene grown on $\mathrm{Cu}$ foils using liquid pyridine via two-step CVD demonstrated high-quality graphene films with dominant graphitic-N, but the $\mathrm{N}$ atomic concentration was low at around 1.6 at.\%. ${ }^{32}$ Although the growth of N-doped graphene has been reported previously, none of the systematic studies were focused on achieving nanographene films with high $\mathrm{N}$ doping concentration at low temperatures, particularly below $200^{\circ} \mathrm{C}$ for cost-effective advanced electronic and electrochemical applications such as sensors and fuel cells. ${ }^{34}$

In this study, we report a viable method to extend the growth capabilities of $\mathrm{N}$-doped nanocrystalline graphene films with enhanced $\mathrm{N}$ doping at low temperatures as low as $100{ }^{\circ} \mathrm{C}$ using a cold-wall plasma-assisted CVD system. This is the lowest temperature that has been reported to date for the growth of $\mathrm{N}$-doped nanocrystalline graphene. In this method, we combine Joule heating and the plasma-assisted growth process at low-temperature regimes and use a $\mathrm{C}_{6} \mathrm{H}_{6} / \mathrm{NH}_{3} / \mathrm{Ar}$ system to produce large-area $\mathrm{N}$-doped nanocrystalline graphene films on a polycrystalline $\mathrm{Ni}$ catalyst in a shorter time as compared to the existing hot-wall CVD method. The influences of the $\mathrm{NH}_{3} / \mathrm{Ar}$ ratio and plasma power on the morphological, chemical composition, structural, and electrical properties of $\mathrm{N}$-doped nanocrystalline graphene films are systematically studied. The findings suggest that the strong synergetic effects of the $\mathrm{NH}_{3} / \mathrm{Ar}$ ratio and plasma power are key to this synthesis route and offer fine-tuning control over 

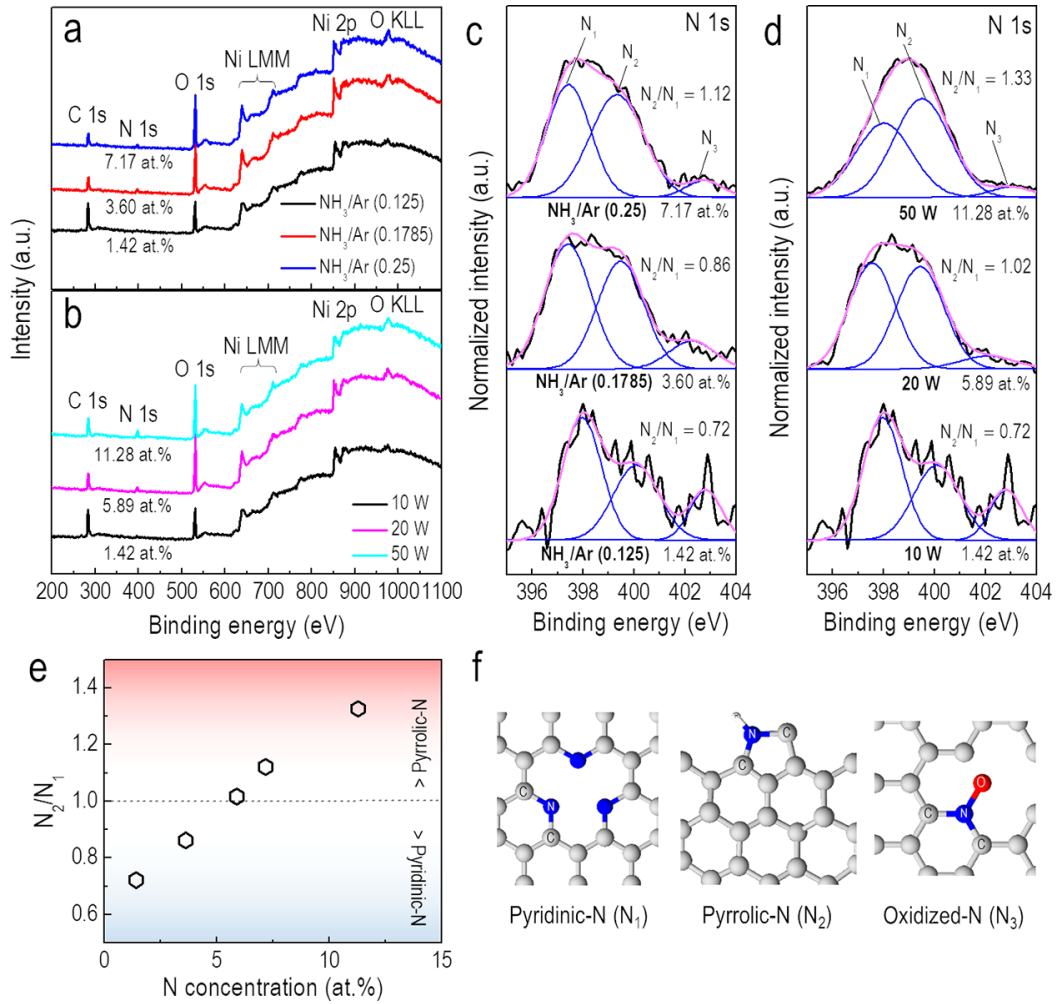

f

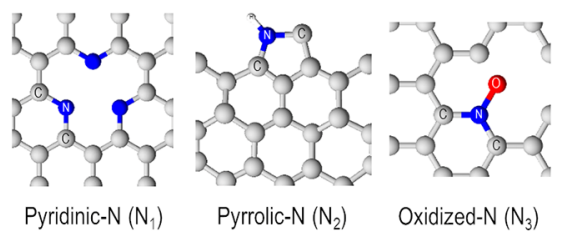

Figure 2. X-ray photoelectron spectroscopy (XPS) spectra of N-doped nanocrystalline graphene films. (a) XPS survey spectra of as-grown samples by varying the $\mathrm{NH}_{3} / \mathrm{Ar}$ ratio at $0.125,0.1785$, and 0.25 . (b) XPS survey spectra of as-grown samples by varying RF plasma power at 10,20 , and 50 W. (c, d) Corresponding core-level of $\mathrm{N} 1 \mathrm{~s}$ spectra. (e) Ratio of pyrrolic-N to pyridinic-N content $\left(\mathrm{N}_{2} / \mathrm{N}_{1}\right)$ as a function of atomic $\mathrm{N}$ concentration. (f) Schematic representation of possible nitrogen bonding configurations. $\mathrm{N}_{1}, \mathrm{~N}_{2}$, and $\mathrm{N}_{3}$ denote pyridinic-N, pyrrolic-N, and oxidized $\mathrm{N}$, respectively.

macroscopic features to enable substantial $\mathrm{N}$ doping into the graphene lattice. The possible growth mechanism with pyridinic-N- and pyrrolic-N-dominated nanocrystalline graphene at low-temperature regimes is also discussed to demonstrate the tunability of $\mathrm{N}$ doping concentration.

\section{RESULTS AND DISCUSSION}

A field-emission scanning electron microscopy (FESEM) system was used to characterize the surface morphologies of the $\mathrm{N}$-doped nanocrystalline graphene films before and after the growth process. The as-deposited $150 \mathrm{~nm}$ thick $\mathrm{Ni}$ on a $\mathrm{SiO}_{2} / \mathrm{Si}(100)$ substrate at room temperature, as shown in Figure 1a, exhibited a continuous film with ultrafine grain size $(<10 \mathrm{~nm})$. After annealing at an elevated temperature of up to $700{ }^{\circ} \mathrm{C}$ in $\mathrm{H}_{2}$ for $30 \mathrm{~min}$, significant grain growth and densification of $\mathrm{Ni}$ film were achieved on the surface of the substrate due to the variation of compressive thermal mismatch coefficient between the $\mathrm{Ni}$ film and $\mathrm{SiO}_{2} / \mathrm{Si}$ substrate. ${ }^{35}$ The as-annealed $\mathrm{Ni}$ film has an average grain size of about $250 \mathrm{~nm}$, and the grains were densely packed without any carbonaceous growth on the $\mathrm{Ni}$ surface (see Figure $1 \mathrm{~b}$ ). This was confirmed by Raman spectrum analysis, in which no $G, D$, and $2 \mathrm{D}$ bands were seen for the samples before and after the annealing process in $\mathrm{H}_{2} / \mathrm{Ar}$ (see Figure $\mathrm{S} 1$ ). In this case, the results suggest that no graphene or amorphous carbon formation was taken place on the Ni surface during the annealing step. After the growth process in $\mathrm{C}_{6} \mathrm{H}_{6}$ / $\mathrm{NH}_{3} / \mathrm{Ar}$ plasma, the grain size of the $\mathrm{Ni}$ film remains unchanged at all. The visibility of color contrast (light and dark region) indicates the formation of nanocrystalline graphene films on the $\mathrm{Ni}$ grains and $\mathrm{SiO}_{2} / \mathrm{Si}(100)$ substrate (see Figure 1c,d). Both lighter and darker regions are representative of thin and thick layers, as commonly reported previously. ${ }^{36}$ It is expected that the high nucleation density and high growth rate of plasma-assisted CVD may cause stacking of graphene in few-layer or multilayer domains, which can be clearly seen in an optical image of the transferred sample (see Figure 1e). Most importantly, the morphology of $\mathrm{N}$-doped nanocrystalline graphene in this work resembles a layer of continuous films on the $\mathrm{SiO}_{2} / \mathrm{Si}(100)$ substrate.

Additional characterization by the visible spectroscopy system has been performed to measure the optical transmittance of $\mathrm{N}$-doped nanocrystalline graphene samples. As reported, light transmittance could identify the number of graphene layers on the quartz substrate, where the wavelength value is commonly taken in the visible range starting from 400 to $800 \mathrm{~nm}$ under incident white light. ${ }^{36}$ Prior to characterization, the as-grown $\mathrm{N}$-doped nanocrystalline graphene films were carefully transferred onto a quartz substrate using the typical wet chemical transfer technique. As shown in Figure 1f, the optical transmittance of $\mathrm{N}$-doped nanocrystalline graphene films exhibits a highly transparent film all over the visible range, in which the values of optical transmittance decrease with increasing growth temperature. The sample grown at $100{ }^{\circ} \mathrm{C}$ exhibits optical transmittance of $97.2 \%$ at $550 \mathrm{~nm}$ and $97.8 \%$ at $700 \mathrm{~nm}$. The high values of optical transmittance in this work are slightly lower compared to that of the typical monolayer graphene $(97.7 \%)$ reported previously. ${ }^{36}$ The slight variation is possibly attributed to the poor coverage of graphene in the form of bilayer or multilayer domains. In addition, the 
Table 1. Direct Growth of the N-Doped Graphene CVD Method from This Present Work and Other Existing Works

\begin{tabular}{|c|c|c|c|c|c|c|}
\hline precursors & $\begin{array}{l}\text { pressure } \\
(\mathrm{Pa})\end{array}$ & catalyst & $\begin{array}{l}\text { temperature } \\
\left({ }^{\circ} \mathrm{C}\right)\end{array}$ & $\begin{array}{l}\text { nitrogen content } \\
(\text { at. } \%)\end{array}$ & main configuration & ref \\
\hline methane/ammonia $\left(\mathrm{CH}_{4} / \mathrm{NH}_{3}\right)$ & atm & $\mathrm{Cu}$ film & 800 & $1.2-8.9$ & graphitic-N & 19 \\
\hline ethylene/ammonia $\left(\mathrm{C}_{2} \mathrm{H}_{4} / \mathrm{NH}_{3}\right)$ & 613 & $\mathrm{Cu}$ foil & 900 & $0-16$ & pyridinic-N & 20 \\
\hline pyridine $\left(\mathrm{C}_{6} \mathrm{H}_{6} \mathrm{~N}\right)$ & 933.3 & $\mathrm{Cu}$ foil & 1000 & 2.4 & pyridinic-N & 22 \\
\hline $\begin{array}{l}\text { poly (dimethylsiloxane }) / \text { hydrogen/nitrogen } \\
\left(\left(\mathrm{C}_{2} \mathrm{H}_{6} \mathrm{OSi}\right)_{n} / \mathrm{H}_{2} / \mathrm{N}_{2}\right)\end{array}$ & 3066.4 & $\mathrm{Cu}$ foil & 700 & $0.9-5.6$ & pyrrolic-N & 27 \\
\hline 1,3,5-triazine $(\mathrm{HCN})_{3}$ & 666.6 & $\mathrm{Cu}$ foil & $700-900$ & $2.1-5.6$ & $\begin{array}{l}\text { pyridinic-N/pyrrolic- } \\
\mathrm{N}\end{array}$ & 42 \\
\hline pyridine $\left(\mathrm{C}_{6} \mathrm{H}_{6} \mathrm{~N}\right)$ & 0.133 & $\mathrm{Cu}$ foil & 950 & 0.18 & graphitic-N & 23 \\
\hline \multirow[t]{2}{*}{ pentachloropyridine $\left(\mathrm{C}_{5} \mathrm{Cl}_{5} \mathrm{~N}\right)$} & 2000 & $\mathrm{Cu}$ foil & $400-600$ & $1.7-8.2$ & pyrrolic-N & 44 \\
\hline & & & $200-300$ & $7.3-8.5$ & graphitic-N & \\
\hline pyridine $\left(\mathrm{C}_{6} \mathrm{H}_{6} \mathrm{~N}\right)$ & atm & $\mathrm{Cu}$ foil & 300 & 1.6 & graphitic-N & 32 \\
\hline \multirow[t]{2}{*}{ benzene/ammonia/argon $\left(\mathrm{C}_{6} \mathrm{H}_{6} / \mathrm{NH}_{3} / \mathrm{Ar}\right)$} & 200 & Ni film & 100 & $1.42-3.60$ & pyridinic-N & present \\
\hline & & & & $5.89-11.28$ & pyrrolic-N & \\
\hline
\end{tabular}

transparency and visual homogeneity of the N-doped nanocrystalline graphene films are also shown in the inset of Figure 1f. For electrical measurements, the as-transferred N-doped nanocrystalline graphene films $(1.0 \mathrm{~cm} \times 1.0 \mathrm{~cm}$ size $)$ on the quartz substrate were characterized using a typical van der Pauw method under ambient air at $300 \mathrm{~K}$ by a Hall-effect measurement system. At a high optical transmittance value of $97.2 \%$, the extracted average sheet resistance $\left(R_{\mathrm{s}}\right)$, sheet concentration $(n)$, Hall mobility $\left(\left|\mu_{\text {Hall }}\right|\right)$, and Hall effect coefficient $\left(\left|R_{\mathrm{Hall}}\right|\right)$ of the $\mathrm{N}$-doped nanocrystalline graphene films were determined to be $3.3 \mathrm{k} \Omega \mathrm{sq}^{-1}, 7.51 \times 10^{13} \mathrm{~cm}^{-2}$, $65.5 \mathrm{~cm}^{2} \mathrm{~V}^{-1} \mathrm{~s}^{-1}$, and $5.41 \mathrm{~cm}^{3} \mathrm{C}^{-1}$, respectively. For comparison with existing plasma-assisted CVD, a plot of sheet resistance versus optical transmittance is shown in Figure 1g. The average sheet resistance of $\mathrm{N}$-doped nanocrystalline graphene films in this work is almost comparable to that of nanocrystalline graphene films grown at much higher temperature regimes. ${ }^{37-40}$

X-ray photoelectron spectroscopy (XPS) is the standard characterization technique to study the nitrogen doping phenomenon. To examine the concentration of atomic $\mathrm{N}$ in the $\mathrm{N}$-doped nanocrystalline graphene films, XPS survey spectra were first measured by scanning the as-grown samples at the lowest growth temperature of $100{ }^{\circ} \mathrm{C}$ with different $\mathrm{NH}_{3} /$ Ar ratios, as shown in Figure 2a,b. The results of the XPS survey scans for all $\mathrm{N}$-doped nanocrystalline graphene films show typical three $\mathrm{C} 1 \mathrm{~s}, \mathrm{~N} 1 \mathrm{~s}$, and $\mathrm{O} 1 \mathrm{~s}$ peaks at 284.8 , $\sim 399.1$, and $\sim 531.2 \mathrm{eV}$ binding energies, respectively. It was observed that the intensity of the $\mathrm{C} 1 \mathrm{~s}$ peak is much lower at a higher $\mathrm{NH}_{3} / \mathrm{Ar}$ ratio and plasma power, while the intensities of other peaks exhibit an opposite trend. Here, the presence of a minor $\mathrm{N}$ 1s peak can be attributed to the $\mathrm{C}-\mathrm{N}$ bonds in the graphene lattice, which is consistent with our previously reported N-doped graphene. ${ }^{41}$ Using a constant RF power of $10 \mathrm{~W}$, the concentration of atomic $\mathrm{N}$ tends to monotonically increase with an increase in the $\mathrm{NH}_{3} / \mathrm{Ar}$ ratio as a result of the high precipitation of $\mathrm{NH}_{3}$ during the growth process. The concentration of atomic $\mathrm{N}$ shows an increasing trend with the values of $1.42,3.60$, and 7.17 at.\% for the $0.125,0.1875$, and 0.25 of $\mathrm{NH}_{3} / \mathrm{Ar}$ ratios, respectively. Similarly, the concentration of atomic $\mathrm{N}$ also tends to increase with an increase in plasma power. The values of the concentration of atomic $\mathrm{N}$ are determined to be $1.42,5.89$, and 11.28 at.\% at 10,20 , and 50 W RF plasma power, respectively. Here, the enhanced $\mathrm{N}$ doping up to 11.28 at.\% is the highest reported $\mathrm{N}$ doping concentration to date for the direct growth CVD process, implying the role of plasma in enabling substantial $\mathrm{N}$ doping at a growth temperature of $100{ }^{\circ} \mathrm{C}$. It is also noted that the $\mathrm{N}$ doped graphene films have a higher $\mathrm{N}$ doping concentration at lower growth temperatures. ${ }^{21,42,43}$ For comparison, the results for the present and previous $\mathrm{N}$-doped graphene are summarized in Table 1 . In this method, the results suggest that a high $\mathrm{N}$ doping concentration is possible to achieve for the growth of $\mathrm{N}$-doped nanocrystalline graphene films at temperatures as low as $100{ }^{\circ} \mathrm{C}$. To confirm the distribution of elemental composition in $\mathrm{N}$-doped nanocrystalline graphene, energy-dispersive X-ray spectroscopy (EDS) elemental mapping analysis was carried out on a mapping area of $18.5 \mu \mathrm{m} \times$ $25 \mu \mathrm{m}$. The EDS results show that the samples grown on the $\mathrm{Ni}$ film at 10,20, and $50 \mathrm{~W}$ RF power consist of the typical C, $\mathrm{O}$, and $\mathrm{N}$ elements, which are distributed uniformly on the top surface (see Figure S2). The N/C atomic ratios for the samples grown on the $\mathrm{Ni}$ film at 10,20, and $50 \mathrm{~W}$ are determined to be $0.072,0.094$, and 0.237 , respectively. Here, the increase in the $\mathrm{N} / \mathrm{C}$ atomic ratio obtained in this work indicates substantial $\mathrm{N}$ doping in the graphene lattice plane.

To further investigate the possible $\mathrm{N}$ bonding configuration in the N-doped nanocrystalline films, the high-resolution XPS scans of $\mathrm{N}$ 1s were carefully carried out at several scan spots of the as-grown samples. After applying the Shirley background subtraction, a Gaussian-Lorentzian product function was used to approximate the line shapes of the fitting components. Figure $2 \mathrm{c}$, d shows the deconvolution of core-level $\mathrm{N} 1 \mathrm{~s}$ spectra of $\mathrm{N}$-doped nanocrystalline graphene films with different $\mathrm{NH}_{3}$ / Ar ratios and plasma power levels. There are three components obtained for the core-level N 1s spectra at $2397.5-398.1$, $\sim 399.4-400.1$, and $\sim 402.2-402.9 \mathrm{eV}$, which correspond to pyridinic- $\mathrm{N}\left(\mathrm{N}_{1}\right)$, pyrrolic- $\mathrm{N}\left(\mathrm{N}_{2}\right)$, and oxidized $\mathrm{N}\left(\mathrm{N}_{3}\right)$, respectively (see Figure $2 \mathrm{f}$ ). Here, no significant peak can be seen at $\sim 401 \mathrm{eV}$, which corresponds to graphitic- $\mathrm{N}$ for all of the as-grown samples, indicating that pyridinic- $\mathrm{N}$ and pyrrolic$\mathrm{N}$ are both preferred to bond with $\mathrm{C}$ atoms over graphitic- $\mathrm{N}$. At a relatively low temperature of $100{ }^{\circ} \mathrm{C}$, none of the $\mathrm{N}$ atoms is expected to substitute a $\mathrm{C}$ atom and bonding with three $\mathrm{C}$ atoms directly in hexagonal lattice structure at the basal plane. Based on the results of core-level $\mathrm{N}$ 1s spectra, it is suggested that the changes of the $\mathrm{N}$ bonding configuration in the $\mathrm{N}$ doped nanocrystalline graphene films are dependent on the growth parameters. At a constant $10 \mathrm{~W}$ RF power, the growth of $\mathrm{N}$-doped nanocrystalline graphene films with $0.125 \mathrm{NH}_{3} / \mathrm{Ar}$ ratio tends to adopt more pyridinic-N over pyrrolic- $\mathrm{N}$ and oxidized $\mathrm{N}$ configuration, especially at the edges or defects. 

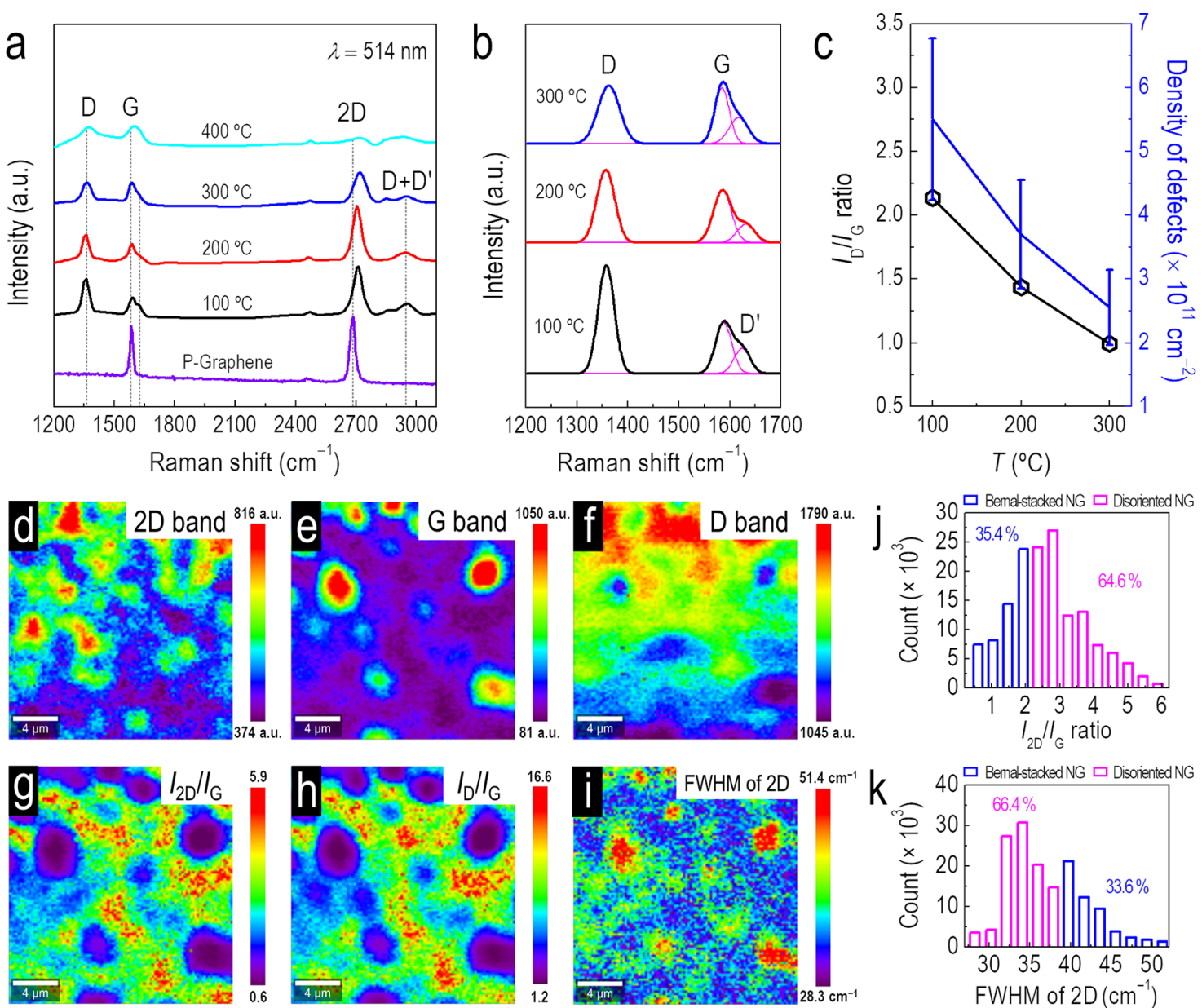

Figure 3. Raman spectra measurements of N-doped nanocrystalline graphene films grown at low-temperature regimes. (a) Raman spectra of Ndoped nanocrystalline graphene films transferred on the $\mathrm{SiO}_{2} / \mathrm{Si}(100)$ substrate at different growth conditions. (b) Deconvoluted profile of the $\mathrm{D}$, $\mathrm{G}$, and $\mathrm{D}^{\prime}$ bands in (a) after baseline correction. (c) Peak intensity ratio of the D band to $\mathrm{G}$ band $\left(I_{\mathrm{D}} / I_{\mathrm{G}}\right)$ and the density of defects $\left(n_{\mathrm{D}}\right)$ as a function of growth temperature $(T)$. ( $\mathrm{d}-\mathrm{i})$ Raman map intensities of the $2 \mathrm{D}$ band, G band, D band, $I_{2 \mathrm{D}} / I_{\mathrm{G}}, I_{\mathrm{D}} / I_{\mathrm{G}}$, and FWHM of the $2 \mathrm{D}$ band. The mapping area of the $\mathrm{N}$-doped nanocrystalline graphene films is $20 \mu \mathrm{m} \times 20 \mu \mathrm{m}$. (j, k) Histogram plots of the peak intensity ratio of the $2 \mathrm{D}$ band to $\mathrm{G}$ band $\left(I_{2 \mathrm{D}} / I_{\mathrm{G}}\right)$ and the full width at half-maximum (FWHM) of the $2 \mathrm{D}$ band indicating the distribution areas of Bernal-stacked and disoriented nanographene $(\mathrm{NG})$ domains.

When the $\mathrm{NH}_{3} / \mathrm{Ar}$ ratio is increased from 0.125 to 0.25 , pyrrolic-N tends to be a more dominant configuration compared to others, in which the ratio of pyrrolic- $\mathrm{N}$ to pyridinic- $\mathrm{N}\left(\mathrm{N}_{2} / \mathrm{N}_{1}\right)$ content increases from 0.72 to 1.12 . A similar trend of increasing pyrrolic- $\mathrm{N}$ is also observed when the $\mathrm{RF}$ power is increased from 10 to $50 \mathrm{~W}$, in which the $\mathrm{N}_{2} / \mathrm{N}_{1}$ increases from 0.72 to 1.33 . Meanwhile, less oxidized $\mathrm{N}$ is observed at a higher $\mathrm{NH}_{3} / \mathrm{Ar}$ ratio and plasma power because this configuration is likely to break from the graphene lattice, and eventually form volatile molecules upon breaking. Based on the values of $\mathrm{N}_{2} / \mathrm{N}_{1}$ in Figure $2 \mathrm{e}$, the $\mathrm{N}$ doping with more pyrrolic- $\mathrm{N}$ than pyridinic- $\mathrm{N}\left(\mathrm{N}_{2} / \mathrm{N}_{1}>1\right)$ can be achieved especially at a higher $\mathrm{N}$ doping concentration ( $\geq 5.89$ at.\%) and vice versa. The findings suggest that pyridinic- $\mathrm{N}$ - and pyrrolic-N-dominated nanocrystalline graphene can be specifically tuned by controlling the $\mathrm{NH}_{3} / \mathrm{Ar}$ ratio and plasma power during the growth process.

Based on the above observations, a possible growth mechanism for the dominant pyridinic- $\mathrm{N}$ or pyrrolic- $\mathrm{N}$ in the graphene lattice based on XPS results is proposed to understand the growth of $\mathrm{N}$-doped nanocrystalline graphene via plasma-assisted CVD. First, it should be noted that the source of dehydrogenation of $\mathrm{C}_{6} \mathrm{H}_{6}$ in this study consists of two parts: plasma and $\mathrm{Ni}$ catalyst. Upon introducing the gas mixture of $\mathrm{C}_{6} \mathrm{H}_{6} / \mathrm{NH}_{3} / \mathrm{Ar}$ into the reaction chamber at $100{ }^{\circ} \mathrm{C}$, the uniform plasma generated by two parallel plates (e.g., gas showerhead and heater stage) on the $\mathrm{Ni}$ surface continuously dissociates $\mathrm{C}_{6} \mathrm{H}_{6}-\mathrm{NH}_{3}$ molecules into highly reactive $\mathrm{C}_{x} \mathrm{H}_{y}$ species (radicals, ions) $(x<6, y<6), \mathrm{NH}_{y}$ species $(y<3)$ and generates reactive $\mathrm{H}$ species in a controlled manner. Through this process, the $\mathrm{H}$ species may contribute to further dissociation of the $\mathrm{C}_{6} \mathrm{H}_{6}-\mathrm{NH}_{3}$ molecules and introduce $\mathrm{H}_{2}$ during the plasma-assisted process. ${ }^{45}$ In addition, the $\mathrm{H}$ and $\mathrm{Ar}$ species also remove impurities and amorphous carbon generated on edges and thus keep the edges active during the nucleation and expansion process. ${ }^{46}$ Although the $\mathrm{C}_{6} \mathrm{H}_{6}$ molecules can be thermally dehydrogenated at low-temperature regimes, the dehydrogenation of $\mathrm{C}_{6} \mathrm{H}_{6}$ molecules partially takes place, ${ }^{47}$ and thus incorporating $\mathrm{NH}_{3}$ molecules is necessary to enhance the efficiency during the plasmaenhanced dissociation reactions. ${ }^{26,48}$ In particular, $\mathrm{H}$ species from the dissociation of the $\mathrm{NH}_{3}$ molecules are likely to hydrogenate with $\mathrm{H}$ species from the dissociated $\mathrm{C}_{x} \mathrm{H}_{y}$ species and introduce additional $\mathrm{H}_{2}$; thus, the dehydrogenation efficiency of $\mathrm{C}_{6} \mathrm{H}_{6}$ increases. Possible chemical interaction to produce $\mathrm{N}$-doped nanocrystalline graphene can be expressed 
by the following equilibrium: $\mathrm{C}_{6} \mathrm{H}_{6}(\mathrm{~g})+2 \mathrm{NH}_{3}(\mathrm{~g})+\mathrm{Ar}(\mathrm{g})$ $\rightleftharpoons \mathrm{N}$-doped graphene $(\mathrm{s})+6 \mathrm{H}_{2}(\mathrm{~g})+\mathrm{Ar}(\mathrm{g})-\mathrm{Q}$ in which $Q$ is the heat. At a low $\mathrm{NH}_{3} / \mathrm{Ar}$ ratio or low plasma power, fewer $\mathrm{H}$ species are likely to initiate the nucleation of small graphitic clusters from the assembly of $\mathrm{C}_{6}$ rings on the Ni surface and result in high coverage of the nanocrystalline graphene film on the $\mathrm{Ni}$ surface. In parallel, more $\mathrm{C}_{x} \mathrm{H}_{y}$ species in the form of $\mathrm{C}_{6}$ rings are generated to form covalent bonds with $\mathrm{NH}_{y}$ species at the edges and graphitic basal plane during the adsorption of $\mathrm{C}_{x} \mathrm{H}_{y}-\mathrm{NH}_{y}$ species on the Ni surface, hence resulting in more pyridinic- $\mathrm{N}$ ( $\mathrm{sp}^{2}$-coordinated, two $\mathrm{N}-\mathrm{C}$ bonds in a hexagon) than pyrrolic-N $\left(\mathrm{sp}^{3}\right.$-coordinated, two $\mathrm{N}-\mathrm{C}$ bonds in a pentagon). This behavior is contrary to the early attempts of low-temperature graphene growth that suffer from low surface coverage and in the form of flakes rather than as a film. ${ }^{31}$ In contrast, at a high $\mathrm{NH}_{3} / \mathrm{Ar}$ ratio or high plasma power, the densities of $\mathrm{C}_{6} \mathrm{H}_{6}$ and $\mathrm{NH}_{3}$ molecules tend to increase more intensely and more $\mathrm{H}$ species are generated during the $\mathrm{C}_{6} \mathrm{H}_{6}-$ $\mathrm{NH}_{3}$ dissociation reactions probably lead to significant edge etching. $\mathrm{NH}_{y}$ species tend to attach to the edges and form $\mathrm{NH}$ terminated edges to increase the energy barrier for $\mathrm{C}$ species attachment. On the other hand, some of the $\mathrm{C}_{6} \mathrm{H}_{6}$ molecules tend to partially dissociate into $\mathrm{C}$ radical fragments or broken graphitic $\mathrm{sp}^{3}$ carbon instead of forming $\mathrm{C}_{6}$ rings for the assembly of the nanocrystalline graphene layer. Therefore, strong interaction between the $\mathrm{NH}_{y}$ species and the graphene edges is expected to take place, especially at the edges or defects, resulting in more pyrrolic- $\mathrm{N}$ than pyridinic- $\mathrm{N}$ due to the strong influence of reactive $\mathrm{NH}_{y}$ species.

Raman spectroscopy is another useful tool to characterize the $\mathrm{N}$-doped nanocrystalline graphene films. The influence of growth temperature on the structural properties of $\mathrm{N}$-doped nanocrystalline graphene film was first investigated and compared with the pristine CVD graphene, as shown in Figure 3a. Raman spectra of pristine CVD graphene present typical intense Raman features: the $G$ band at $1583 \mathrm{~cm}^{-1}$ and the $2 \mathrm{D}$ band at $2684 \mathrm{~cm}^{-1}$. In addition to these two peaks, the $\mathrm{N}$-doped nanocrystalline graphene film at lower growth temperature presents a D band of much stronger peak intensity located at $1357 \mathrm{~cm}^{-1}$, which is activated by intervalley scattering, indicating the presence of higher defects or impurities from the substitution of $\mathrm{N}$ atoms into the graphene lattice. Meanwhile, at higher growth temperatures, the peak intensity of the $2 \mathrm{D}$ band in the $\mathrm{N}$-doped nanocrystalline graphene film is much weaker compared to that in pristine graphene, which is consistent with the previously reported $\mathrm{N}$ doped graphene. ${ }^{49}$ However, the peak intensity of the $2 \mathrm{D}$ band almost deteriorates for the sample grown at $400{ }^{\circ} \mathrm{C}$, which indicates the formation of amorphous carbon. This could be attributed to the higher electron-hole scattering rate from either the $\mathrm{N}$-induced electron doping or lattice defects. ${ }^{50}$ Additional weak $\mathrm{D}^{\prime}$ and $\mathrm{D}+\mathrm{D}^{\prime}$ peaks located at 1624 and $2950 \mathrm{~cm}^{-1}$ are also noticeable for the samples grown at 100 , 200 , and $300{ }^{\circ} \mathrm{C}$, which are activated by intravalley scattering and combination of phonons with different momenta around $\mathrm{K}$ and $\Gamma$ points, respectively. Here, the $\mathrm{D}^{\prime}$ peak is merged into the $G$ peak due to intrinsic defects in the nanocrystalline graphene films. ${ }^{51}$ From deconvolution of Raman spectra, as shown in Figure 3b, a sharp G peak profile is expected for the as-grown samples that is distinct from those of amorphous carbon and diamondlike films grown by the plasma method. ${ }^{52}$ In addition, the shift of Raman peaks can also provide doping information of the graphene lattice. ${ }^{53}$ In comparison to the pristine graphene, the $\mathrm{G}$ and $2 \mathrm{D}$ bands for the sample grown at $100{ }^{\circ} \mathrm{C}$ are shifted to the higher frequencies with an average blue shift of $\sim 3.4$ and $\sim 18.7 \mathrm{~cm}^{-1}$, respectively. Noted that the blue shift in the $\mathrm{G}$ band is due to the presence of pyridinic-N and pyrrolic-N, which is in accordance with reported $\mathrm{N}$-doped graphene. ${ }^{54}$ This means that our nanocrystalline graphene films are successfully doped by $\mathrm{N}$ atoms.

Generally, the peak intensity ratio of D band to $\mathrm{G}$ band $\left(I_{\mathrm{D}} /\right.$ $I_{\mathrm{G}}$ ) indicates the degree of defects in in-plane graphene, ${ }^{55}$ which usually shows a strong dependence on the growth temperature. In this study, the mean values of the $I_{\mathrm{D}} / I_{\mathrm{G}}$ ratio are expected to increase from 1.0 to 2.13 when decreasing the growth temperature from 300 to $100{ }^{\circ} \mathrm{C}$ (see Figure 3a). The mean values of $I_{\mathrm{D}} / I_{\mathrm{G}}$ in this work are much higher than that of typical polycrystalline $\mathrm{N}$-doped graphene $\left(I_{\mathrm{D}} / I_{\mathrm{G}}=\sim 0.3-0.4\right)$ produced by the high-temperature CVD method. ${ }^{56}$ From the mean values of $I_{\mathrm{D}} / I_{\mathrm{G}}$, the density of defects of the $\mathrm{N}$-doped nanocrystalline graphene can be evaluated using the following general equation: ${ }^{55} n_{\mathrm{D}}=\left((1.8 \pm 0.5) \times 10^{22}\right) \cdot \lambda^{-4} \cdot\left(I_{\mathrm{D}} / I_{\mathrm{G}}\right)$, where $\lambda$ is the laser excitation wavelength used for the Raman measurements. Assuming that $\mathrm{N}$ doping is uniform in the graphene film, here, we estimate that the average defect densities of the $\mathrm{N}$-doped nanocrystalline graphene are $5.49 \times$ $10^{11}, 3.70 \times 10^{11}$, and $2.55 \times 10^{11} \mathrm{~cm}^{-2}$ for the growth temperatures of 100,200 , and $300{ }^{\circ} \mathrm{C}$, respectively (see Figure $3 c)$. The high $I_{\mathrm{D}} / I_{\mathrm{G}}$ in this work also reflects a common feature of polycrystalline nanodomains in the graphene grown using plasma. From the peak intensity ratio of the D band to $\mathrm{G}$ band, it is possible to estimate the graphitic domain size. ${ }^{57}$ The domain size $L_{\mathrm{a}}$ can be estimated by the Tuinstra-Koenig relation $L_{\mathrm{a}}=\left(2.4 \times 10^{-10}\right) \cdot \lambda^{4} \cdot\left(I_{\mathrm{D}} / I_{\mathrm{G}}\right)^{-1}$. In particular, this yields an average domain size of $7.86 \mathrm{~nm}$ for the growth temperature of $100{ }^{\circ} \mathrm{C}$, about 1 order of magnitude smaller than that of typical pristine graphene $(>100 \mathrm{~nm})$. This value indicates that the deposited graphene is not pure singlecrystalline but nitrogen-containing polycrystalline graphene.

Next, Raman mapping measurements were also employed to further investigate the structural properties of the $\mathrm{N}$-doped nanocrystalline graphene film at the lowest growth temperature of $100{ }^{\circ} \mathrm{C}$. Large-area Raman mapping images of the as-grown sample within a $20 \mu \mathrm{m} \times 20 \mu \mathrm{m}$ area were carefully obtained for the main $2 \mathrm{D}, \mathrm{G}$, and $\mathrm{D}$ bands, as shown in Figure $3 \mathrm{~d}-\mathrm{f}$. Among these bands, the results of the $\mathrm{D}$ band at $1357 \mathrm{~cm}^{-1}$ show the highest values of intensity due to a high number of defects and high amount of $\mathrm{N}$ dopants in the graphene lattice, which is relatively consistent with the results of Raman spectra in Figure 3a. On the other hand, the results of the 2D band at $2703 \mathrm{~cm}^{-1}$ and the $\mathrm{G}$ band at $1587 \mathrm{~cm}^{-1}$ show fair values of intensity, indicating that the as-grown sample possesses high coverage of nanocrystalline graphene films over the large-area substrate. To examine the stacking order of nanocrystalline graphene films, further analysis of the Raman intensity map of $I_{2 \mathrm{D}} / I_{\mathrm{G}}$ and the full width at half-maximum (FWHM) of the $2 \mathrm{D}$ band was performed, as shown in Figure 3g,i. It is worth noting that the stacking order is determined based on the following $I_{2 \mathrm{D}} / I_{\mathrm{G}}$ and FWHM values of the $2 \mathrm{D}$ band: 0.6-2.0 $\left(I_{2 \mathrm{D}} / I_{\mathrm{G}}\right)$ and $41.0-51.4 \mathrm{~cm}^{-1}$ (FWHM of 2D) are for Bernal-stacked nanocrystalline graphene, whereas $2.1-5.9\left(I_{2 \mathrm{D}} / I_{\mathrm{G}}\right)$ and 28.3$40.5 \mathrm{~cm}^{-1}$ (FWHM of 2D) are for disoriented nanocrystalline graphene. Here, the distribution of the stacking order in nanocrystalline graphene is shown in the histogram plots of $I_{2 \mathrm{D}} / I_{\mathrm{G}}$ and FWHM of $2 \mathrm{D}$ (see Figure $3 \mathrm{j}, \mathrm{k}$ ), where both show comparable results. The disoriented nanocrystalline graphene 

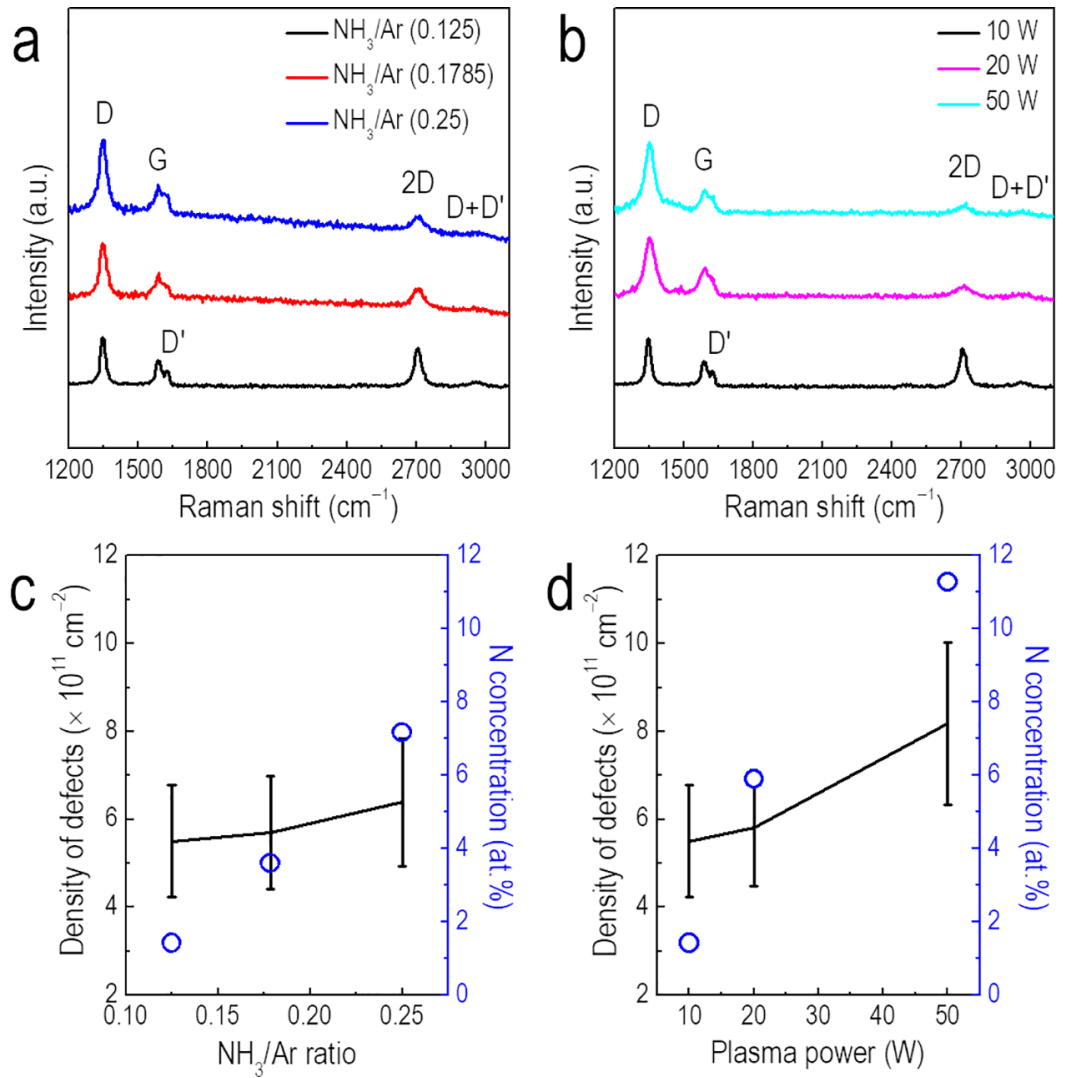

Figure 4. Raman spectra of $\mathrm{N}$-doped nanocrystalline graphene films grown on the $\mathrm{Ni}$ film $/ \mathrm{SiO}_{2} / \mathrm{Si}(100)$ substrate with different $(\mathrm{a}) \mathrm{NH} / \mathrm{Ar}$ ratios and (b) plasma power levels. Density of defects and $\mathrm{N}$ doping concentration as a function of (c) $\mathrm{NH}_{3} / \mathrm{Ar}$ ratio and (d) plasma power.
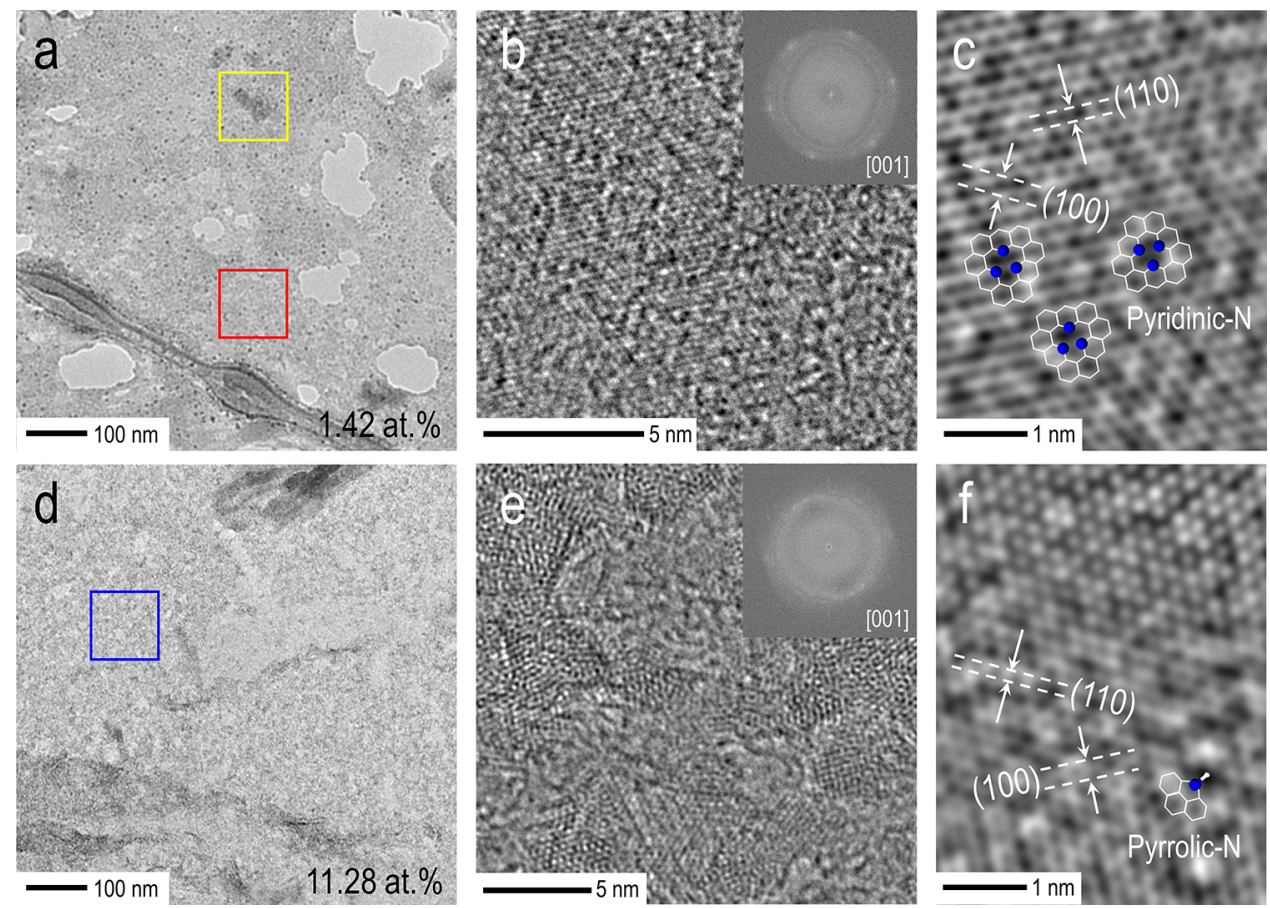

Figure 5. Characterization of the atomic structure of $\mathrm{N}$-doped nanocrystalline graphene films grown at $100{ }^{\circ} \mathrm{C}$. (a) TEM image of $\mathrm{N}$-doped nanocrystalline graphene films with an atomic $\mathrm{N}$ doping concentration of 1.42 at.\%. (b) HR-TEM imaging in a red square area in (a); the inset of (b) is the corresponding fast Fourier transform FFT pattern displaying the characteristic of the single-crystalline lattice structure. (c) Fourier filtered HR-TEM image showing the pyridinic-N configuration. (d) TEM image of N-doped nanocrystalline graphene films with an atomic $\mathrm{N}$ doping concentration of 11.28 at.\%. (e) HR-TEM imaging in a blue square area in (d); the inset of (e) is the corresponding fast Fourier transform FFT pattern showing the typical Debye-Scherrer-type ring pattern. (f) Fourier filtered HR-TEM image showing the pyrrolic-N configuration. 

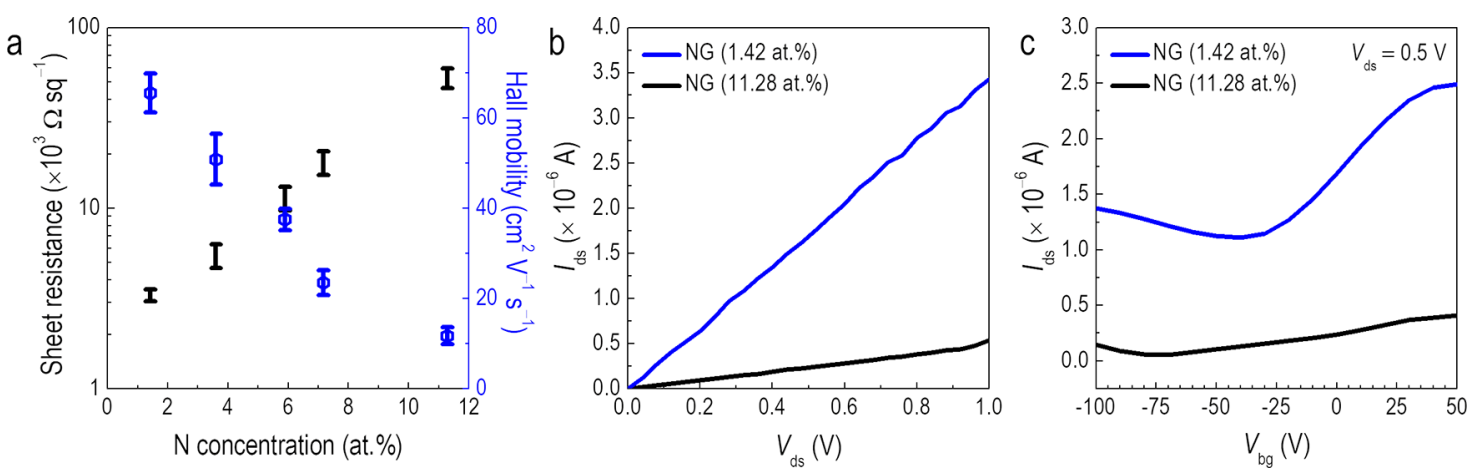

Figure 6. Electrical characterization of N-doped nanocrystalline graphene films. (a) Sheet resistance and Hall mobility as a function of the N doping concentration. (b) Source-drain current $\left(I_{\mathrm{sd}}\right)$-source-drain voltage $\left(V_{\mathrm{sd}}\right)$ characteristics at zero gate voltage $\left(V_{\mathrm{bg}}\right)$. (c) $I_{\mathrm{sd}}-V_{\mathrm{bg}}$ transfer characteristics at a constant $V_{\mathrm{sd}}$ of $0.5 \mathrm{~V}$ for the $\mathrm{N}$-doped nanocrystalline graphene (NG) films with $\mathrm{N}$ doping concentrations of 1.42 and 11.28 at. $\%$.

has relatively dominant coverage areas with $64.6-66.4 \%$, while the remaining areas of $33.6-35.6 \%$ are covered by the Bernalstacked nanocrystalline graphene. The observations also suggest that the highly disoriented nanocrystalline graphene region mostly correlates to a high number of defects, according to the Raman intensity map of $I_{\mathrm{D}} / I_{\mathrm{G}}$ (see Figure $3 \mathrm{~h}$ ).

To confirm the tunability of the $\mathrm{N}$ doping concentration in $\mathrm{N}$-doped nanocrystalline graphene, we used Raman measurements to correlate the defect density of the as-grown samples with the $\mathrm{N}$ doping concentration at different $\mathrm{NH}_{3} / \mathrm{Ar}$ ratios and plasma power levels (refer to Figure 2a,b). Figure $4 a, b$ shows the Raman spectra of the as-grown samples with different $\mathrm{NH}_{3} / \mathrm{Ar}$ ratios and plasma power extracted from the Raman mapping measurements (see Figure S4). It was observed that the intensity of the $\mathrm{D}$ band increases, whereas the intensity of the $2 \mathrm{D}$ band decreases with increasing $\mathrm{NH}_{3} / \mathrm{Ar}$ ratio and plasma power, suggesting substantial $\mathrm{N}$ doping accompanied by the appearance of structural defects. By varying the $\mathrm{NH}_{3} /$ Ar ratio, the $I_{\mathrm{D}} / I_{\mathrm{G}}$ ratio shows an increasing trend with the mean values of $2.13,2.21$, and 2.48 for the $0.125,0.1875$, and $0.25 \mathrm{NH}_{3} /$ Ar ratios, respectively. Also, an increase in plasma power may result in a drastic increase in the $I_{\mathrm{D}} / I_{\mathrm{G}}$ ratio with the mean values of $2.13,2.25$, and 3.17 for the 10, 20, and $50 \mathrm{~W}$ RF plasma power levels, respectively. The density of defects $\left(n_{\mathrm{D}}\right)$ in relation to the $\mathrm{N}$ doping concentration is presented in Figure $4 \mathrm{c}$,d. From the graphs, the estimated $n_{\mathrm{D}}$ of the $\mathrm{N}$-doped nanocrystalline graphene is proportional to the $\mathrm{NH}_{3} / \mathrm{Ar}$ ratio and plasma power, which correlates well with the increase in the $\mathrm{N}$ doping concentration as discussed previously.

The atomic structure of the $\mathrm{N}$-doped nanocrystalline graphene film was characterized by high-resolution transmission electron microscopy (HR-TEM). Figure 5a,c displays the low-resolution bright-field TEM image of $\mathrm{N}$-doped nanocrystalline graphene with $\mathrm{N}$ doping concentrations of 1.42 and 11.28 at.\%, respectively. The $\mathrm{N}$-doped nanocrystalline graphene at a low $\mathrm{N}$ doping concentration (1.42 at.\%) transferred on a lacey carbon-coated $\mathrm{Cu}$ grid illustrates a few hundred square nanometer thin layer that is highly electron transparent in comparison to the lacey carbon support. Meanwhile, the one at a high $\mathrm{N}$ doping concentration (11.28 at.\%) displays a destructive thin layer with more uneven features. The most transparent areas are likely identified as a thin layer of nanocrystalline graphene, whereas the dark areas indicate some structural folds and holes that were probably formed due to improper handling of the sample during the wet chemical transfer process. Figure $5 b$ shows the HR-TEM image of $\mathrm{N}$-doped nanocrystalline graphene at a low $\mathrm{N}$ doping concentration (1.42 at.\%) taken from the selected red square area in Figure 6a. Both HR-TEM and its corresponding fast Fourier transform (FFT) pattern show the single-crystalline nature of the graphitic domains in the hexagonal lattice form with some defects at the basal plane, which are quite similar to the reported $\mathrm{N}$-doped graphene from previous works. ${ }^{58,59}$ Conversely, the HR-TEM image of $\mathrm{N}$-doped nanocrystalline graphene at a high $\mathrm{N}$ doping concentration (11.28 at.\%) reveals small graphitic domains in a polycrystalline structure, which was further confirmed by the typical Debye-Scherrertype ring pattern from the FFT pattern (see Figure 5e). From the HR-TEM analysis, the domain sizes of the $\mathrm{N}$-doped nanocrystalline films with $\mathrm{N}$ doping concentrations of 1.42 and 11.28 at.\% are estimated to be $5.22 \pm 0.93$ and $3.16 \pm 0.88$ $\mathrm{nm}$, respectively.

To resolve an individual $\mathrm{C}$ atom in the hexagonal packing arrangement and provide the topography of an individual $\mathrm{N}$ dopant site, the HR-TEM image was carefully postprocessed by a typical Fourier mask filtering method. ${ }^{60}$ From the images of Fourier filtered HR-TEM of the N-doped nanocrystalline graphene, as shown in Figure $5 c, f$, the atomic-scale measurements reveal lattice spacings of $\sim 0.25$ and $\sim 0.14 \mathrm{~nm}$ corresponding to the (100) and (110) planes, respectively. In addition, the $\mathrm{C}$ atoms that are bonding with the $\mathrm{N}$ atom in the pyridinic- $\mathrm{N}$ and pyrrolic-N configurations within the graphene lattice are also observed, which correlate well with the XPS results in this study. The triangular dark spots surrounded by bright spots in graphene at the basal plane are assigned to the pyridinic- $\mathrm{N}$ configuration (see Figure 5c), whereas the dark spots associated with vacancy defects at the edges or defects are probably attributed to the incorporated $\mathrm{N}$ atoms corresponding to the pyrrolic- $\mathrm{N}$ configuration (see Figure 5f). Our observation here is quite similar to the previously reported graphene with pyridinic- $\mathrm{N}$ and pyrrolic$\mathrm{N} .{ }^{61}$ Overall, even though the low-temperature growth was successfully demonstrated here, further optimizations of the growth parameters are still needed to achieve high-quality graphene films while maintaining substantial $\mathrm{N}$ doping in the graphene lattice plane. For example, the design of a highquality single-crystalline catalyst would be a better route for the low-temperature plasma-assisted CVD methods in the near future. 

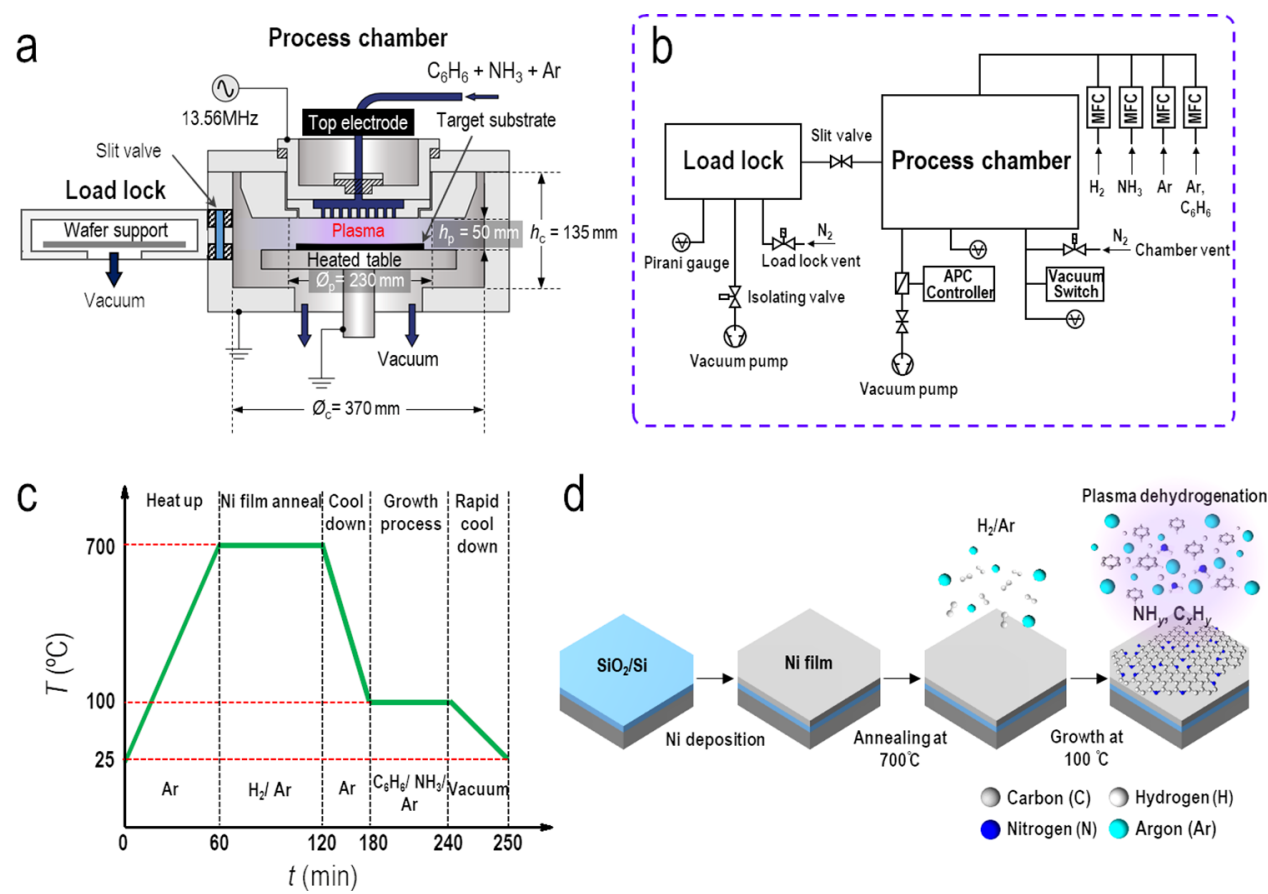

Figure 7. Experimental setup of low-temperature growth of N-doped nanocrystalline graphene films. (a) Schematic representation of the cold-wall plasma-assisted CVD method. (b) Layout of the vacuum system of the plasma-assisted CVD method. (c) Schematic diagram of the reaction temperature $(T)$ versus duration $(t)$ for the optimized growth parameters. (d) Schematic representation of the overall growth process of N-doped nanocrystalline graphene films.

Electrical measurements based on the van der Pauw method were first performed using a Hall-effect measurement system in ambient air at $300 \mathrm{~K}$ to evaluate the sheet resistance $\left(R_{\mathrm{s}}\right)$ and Hall mobility $\left(\mu_{\text {Hall }}\right)$ of $\mathrm{N}$-doped nanocrystalline graphene films. The results of sheet resistance and Hall mobility as a function of the $\mathrm{N}$ doping concentration are shown in Figure 6 a. It was revealed that the measured sheet resistance of $\mathrm{N}$ doped nanocrystalline graphene films increases from $3.3 \pm 0.3$ to $52.8 \pm 6.7 \mathrm{k} \Omega ~ s q^{-1}$ with an increase in the $\mathrm{N}$ doping concentration. As a direct consequence of the increase in the sheet resistance, it was observed that the Hall mobility of the charge carriers decreases from $65.5 \pm 4.4$ to $11.7 \pm 1.9 \mathrm{~cm}^{2}$ $\mathrm{V}^{-1} \mathrm{~s}^{-1}$ with an increase in the $\mathrm{N}$ doping concentration. In this case, the Hall mobility mainly decreases due to the high scattering of defects and disorders in the graphene lattice, which is related to a high degree of $\mathrm{N}$ doping. Noted that the $\mathrm{N}$-doped nanocrystalline graphene films dominated by pyridinic- $\mathrm{N}$ and pyrrolic- $\mathrm{N}$ are usually accompanied by the presence of defects that tend to localize the charge carrier transport. To further study the influence of $\mathrm{N}$ doping concentration on the electrical properties of $\mathrm{N}$-doped nanocrystalline graphene films, a back-gated field-effect transistor (FET) using the $\mathrm{N}$-doped nanocrystalline graphene films was fabricated by a standard photolithography process and characterized using a source meter unit (SMU) system (Keithley 236) in ambient air at $300 \mathrm{~K}$. The FET structure consists of back gating of a p-type $\mathrm{Si}, 500 \mathrm{~nm}$ thick $\mathrm{SiO}_{2}$ layer as gate oxidation, $\mathrm{N}$-doped nanocrystalline graphene, and metal source and drain contacts ( $\mathrm{Au} / \mathrm{Cr}$ electrodes with 120/ $60 \mathrm{~nm}$ thickness). Figure $6 \mathrm{~b}$ shows the typical source-drain current $\left(I_{\mathrm{sd}}\right)$ versus the source-drain voltage $\left(V_{\mathrm{sd}}\right)$ for the fabricated FET devices with the $\mathrm{N}$-doped nanocrystalline graphene films at low (1.42 at.\%) and high (11.28 at.\%) $\mathrm{N}$ doping concentrations. Both devices exhibit a linear $I_{\mathrm{sd}}-V_{\text {sd }}$ curve at zero gate voltage $\left(V_{\mathrm{bg}}\right)$ with low contact resistance, suggesting a good Ohmic contact between the $\mathrm{N}$-doped nanocrystalline graphene films and the $\mathrm{Au} / \mathrm{Cr}$ electrodes.

Figure $6 \mathrm{c}$ shows the source-drain current $\left(I_{\mathrm{sd}}\right)$ versus gate voltage $\left(V_{\mathrm{bg}}\right)$ at a constant $V_{\text {sd }}$ of $0.5 \mathrm{~V}$ for the fabricated FET devices with the $\mathrm{N}$-doped nanocrystalline graphene films at low (1.42 at.\%) and high (11.28 at.\%) $\mathrm{N}$ doping concentrations, at which the charge transport exhibits asymmetry in electron and hole conduction. It can be seen that $I_{\text {sd }}$ increases with increasing positive gate bias for both devices, indicating an $n$ type semiconductor behavior. ${ }^{32}$ In addition, the Dirac gate voltage was observed at -40 and $-70 \mathrm{~V}$ for the devices with $\mathrm{N}$ doping concentrations at 1.42 and 11.28 at.\%, respectively, suggesting the predominant electron transport in the $\mathrm{N}$-doped nanocrystalline graphene films. Here, a clear trend toward a negative shift of the Dirac gate voltage (from -40 to $-70 \mathrm{~V}$ ) could be attributed to the increase in electron density distribution with increasing $\mathrm{N}$ doping concentration. ${ }^{42}$ From the transfer characteristics of the devices, the electron and hole mobilities were extracted by estimating the linear region of $I_{\mathrm{sd}}-V_{\mathrm{bg}}$ curves using equation ${ }^{62} \mu=\left(l / w C_{\mathrm{ox}} V_{\mathrm{sd}}\right) /\left(\Delta I_{\mathrm{sd}} / \Delta V_{\mathrm{bg}}\right)$, where $l$ and $w$ are the channel length $(50 \mu \mathrm{m})$ and width $(50$ $\mu \mathrm{m})$, respectively, and $C_{\mathrm{ox}}$ is the gate oxide capacitance per unit area (ca. $69.02 \mathrm{nF} \mathrm{cm}^{-2}$ ) for the $500 \mathrm{~nm}$ thick $\mathrm{SiO}_{2}$ layer. The electron and hole mobilities of the device at a low $\mathrm{N}$ doping of 1.42 at.\% are 57.7 and $12.7 \mathrm{~cm}^{2} \mathrm{~V}^{-1} \mathrm{~s}^{-1}$, respectively. Meanwhile, at a high $\mathrm{N}$ doping of 11.28 at.\%, the electron and hole mobilities of the device are 9.1 and $8.7 \mathrm{~cm}^{2} \mathrm{~V}^{-1} \mathrm{~s}^{-1}$, respectively. In this case, the electron and hole mobilities decrease upon a further increase in the $\mathrm{N}$ doping concentration and this finding is also consistent with the observation of a decrease in the Hall mobility of the charge carriers mentioned above (see Figure 6b). It should be noted that $\mathrm{N}$ doping introduces a significant number of defects and causes changes 
in the structural and electronic properties of graphitic materials. ${ }^{19,42}$ As a general observation, a high density of defects, resulting from high $\mathrm{N}$ doping in the form of pyridinic$\mathrm{N}$ and pyrrolic- $\mathrm{N}$, leads to a decrease in the charge carrier mobility as a consequence of the large number of $\pi$ electrons localized around the defect sites. Therefore, in this work, the changes in the electron and hole mobilities in relation to the $\mathrm{N}$ doping are well correlated with the density of defects in $\mathrm{N}$ doped nanocrystalline graphene films.

\section{CONCLUSIONS}

In summary, we reported an attempt of the direct growth of $\mathrm{N}$ doped nanocrystalline graphene films via a low-temperature cold-wall plasma-assisted CVD method in a $\mathrm{C}_{6} \mathrm{H}_{6} / \mathrm{NH}_{3} / \mathrm{Ar}$ system. It was found that fully covered $\mathrm{N}$-doped nanocrystalline graphene films can be effectively grown on a pretreated $\mathrm{Ni}$ film at low-temperature regimes as low as $100{ }^{\circ} \mathrm{C}$. Unlike existing $\mathrm{N}$-doped graphene, the as-grown films here are composed of highly defective $\mathrm{N}$-containing polycrystalline nanodomains. The influences of the $\mathrm{NH}_{3} / \mathrm{Ar}$ ratio and plasma power on the $\mathrm{N}$ doping were systematically investigated, wherein the synergetic effects are key to the fine-tuning graphene growth with pyridinic-N or pyrrolic-N at low temperatures. At a low $\mathrm{NH}_{3} / \mathrm{Ar}$ ratio or low plasma power, the resulting graphene growth favored more pyridinic- $\mathrm{N}$ than pyrrolic-N. Conversely, at a high $\mathrm{NH}_{3} /$ Ar ratio or high plasma power, pyrrolic-N-dominated graphene growth, which is mostly associated with defects at the edges, presented substantial $\mathrm{N}$ doping up to values of 11.28 at.\%. In addition, the $\mathrm{N}$-doped nanocrystalline graphene films dominated by pyridinic-N and pyrrolic-N exhibit n-type semiconductor behavior with a strong asymmetry in electron-hole conduction under ambient air conditions. Our findings here provide significant progress toward the establishment of a highthroughput plasma-assisted CVD method and also contribute to designing novel materials with a practical strategy of heteroatom nitrogen doping at low temperatures for future transparent nanodevices.

\section{EXPERIMENTAL SECTION}

4.1. Growth of N-Doped Nanocrystalline Graphene Films. A $150 \mathrm{~nm}$ thick polycrystalline Ni film (99.99\%, Kurt J. Lesker), as a catalyst, was deposited on the $\mathrm{SiO}_{2} / \mathrm{Si}$ (100) substrate via a radio frequency magnetron sputtering system (Edwards TF-600) at a base pressure of $0.2 \mathrm{~Pa}$ and room temperature. The growth of $\mathrm{N}$-doped nanocrystalline graphene films was performed in a cold-wall plasma-assisted CVD system (Oxford Instruments, PlasmalabSystem 100), as illustrated in Figure $7 \mathrm{a}, \mathrm{b}$. Prior to the growth process, the samples were annealed at $700{ }^{\circ} \mathrm{C}$ by direct Joule heating under continuous $100 \mathrm{sccm}$ hydrogen $\mathrm{H}_{2}$ (99.999\%) and $100 \mathrm{sccm}$ argon $\mathrm{Ar}(99.99999 \%)$ at a pressure of $200 \mathrm{~Pa}$ for $60 \mathrm{~min} . \mathrm{H}_{2}$ gas was introduced into the chamber to further remove the remaining carbon and oxygen impurities. The samples were then cooled down to the desired growth temperature (400, 300, 200, and $100{ }^{\circ} \mathrm{C}$, respectively) in an Ar atmosphere. To confirm the contaminant-free samples before and after the annealing step, the samples were characterized and verified by Raman measurements (see Figure S1). For the growth process, after reaching the desired temperature by direct Joule heating, the growth of $\mathrm{N}$-doped nanocrystalline graphene films was carried out in a mixture ratio of 1:1:8 $\left(\mathrm{C}_{6} \mathrm{H}_{6} / \mathrm{NH}_{3} / \mathrm{Ar}\right)$ at the same pressure with a minimum of $10 \mathrm{~W}$ plasma power for $1 \mathrm{~h}$. Noted that the uniform plasma field generated on the surface can cover up to a diameter of $\sim 230 \mathrm{~mm}$ with a vertical distance of $\sim 50 \mathrm{~mm}$. For this system, the liquid benzene $\left(\mathrm{C}_{6} \mathrm{H}_{6}\right)$ source $(\geq 99.9 \%$, Sigma-Aldrich) that was kept in a bubbler at room temperature was transported into the reaction chamber with a $20 \mathrm{sccm}$ Ar flow rate as the carrier gas, while purified Ar with $160 \mathrm{sccm}$ flow rate (99.99999\%) and $\mathrm{NH}_{3}$ (99.999\%) with 20 sccm flow rate introduced during the growth process were transported separately. In this work, the influences of the $\mathrm{NH}_{3}$ / Ar flow rate ratio $(0.125,0.1875$, and 0.25$)$ and radio frequency $(\mathrm{RF})$ power $(10,20$, and $50 \mathrm{~W})$ on the growth of nanocrystalline graphene films were further investigated at 100 ${ }^{\circ} \mathrm{C}$. Finally, the samples were transferred to a load lock and rapidly cooled to room temperature in vacuum $(<0.133 \mathrm{~Pa})$. The overall growth process in this work is shown in Figure $7 \mathrm{c}, \mathrm{d}$.

4.2. Sample Characterization. Prior to the characterization of $\mathrm{N}$-doped nanocrystalline graphene films, the asgrown samples were transferred onto $\mathrm{SiO}_{2} / \mathrm{Si}$ (100), a quartz substrate, and a lacey carbon-coated $\mathrm{Cu}$ grid by a wet chemical transfer method. ${ }^{29}$ The transfer was initiated with spin coating of $100 \mathrm{~nm}$ thick poly(methyl methacrylate) (PMMA) on the as-grown samples $(1 \mathrm{~cm} \times 1 \mathrm{~cm})$, followed by curing the samples at $80{ }^{\circ} \mathrm{C}$ on a hot plate for $5 \mathrm{~min}$ and immersing the whole samples in $0.1 \mathrm{M}$ ferric chloride $\left(\mathrm{FeCl}_{3}\right)$ for a sufficiently long time to remove the $\mathrm{Ni}$ film. The resulting $\mathrm{N}$-doped nanocrystalline graphene films with PMMA in the form of a transparent film were transferred in the deionized water to clean the $\mathrm{Ni}$ residues and the $\mathrm{FeCl}_{3}$ etching agents. Then, the transparent film was transferred to the target substrate, where the remaining PMMA was removed in acetone. The morphology and structural properties of the transferred samples were characterized by a field-emission scanning electron microscopy (FESEM) system (JEOL, JSM-7500F) operating at an accelerating voltage of $2.0 \mathrm{kV}$ and a highresolution transmission electron microscopy (HR-TEM) system (JEOL, JEM-2010) operating at an accelerating voltage of $200 \mathrm{kV}$. To investigate their elemental composition and $\mathrm{N}$ doping configuration in the graphene film, X-ray photoelectron spectroscopy (XPS) measurements were carried out using an X-ray photoelectron spectrometer system (Scanning XPS Microprobe, PHI Quantera II). The XPS system was operated under the conditions of a maximum photon electron of $600 \mathrm{eV}$ with $0.1 \mathrm{eV}$ kinetic energy steps for a narrow scan. For the structural analysis of $\mathrm{N}$-doped nanocrystalline graphene films, Raman spectra measurements were performed at room temperature with laser excitation at $514 \mathrm{~nm}$ using a Raman spectroscopy system (WITec $\alpha$ 300). For the electrical measurements, a Hall-effect measurement system (Ecopia, HMS-5300) was used to characterize the transferred N-doped nanocrystalline graphene films on the $\mathrm{SiO}_{2} / \mathrm{Si}$ substrate in ambient air at $300 \mathrm{~K}$. In the same conditions, the back-gated field-effect transistor (FET), utilizing the $\mathrm{N}$-doped nanocrystalline graphene films, was also characterized using a source meter unit (SMU) system (Keithley 236).

\section{ASSOCIATED CONTENT}

\section{Supporting Information}

The Supporting Information is available free of charge at https://pubs.acs.org/doi/10.1021/acsomega.1c01520. 
Raman spectra analysis of the samples before and after the annealing process (Figure S1), energy-dispersive Xray spectroscopy (EDS) elemental mapping analysis (Figure S2), X-ray diffraction (XRD) pattern of the $\mathrm{N}$ doped nanocrystalline graphene films on the polycrystalline Ni film (Figure S3), and Raman mapping measurements of $\mathrm{N}$-doped nanocrystalline graphene films (Figure S4) (PDF)

\section{AUTHOR INFORMATION}

\section{Corresponding Authors}

Muhammad Aniq Shazni Mohammad Haniff - Institute of Microengineering and Nanoelectronics, Universiti Kebangsaan Malaysia, 43600 Bangi, Malaysia; 이이이.org/ 0000-0003-3980-3460; Email: aniqshazni@ukm.edu.my

Abdul Manaf Hashim - Advanced Devices and Material Engineering Research Lab, Department of Electronic Systems Engineering, Malaysia-Japan International Institute of Technology, Universiti Teknologi Malaysia, 51400 Kuala Lumpur, Malaysia; Email: abdmanaf@utm.my

\section{Authors}

Nur Hamizah Zainal Ariffin - Advanced Devices and Material Engineering Research Lab, Department of Electronic Systems Engineering, Malaysia-Japan International Institute of Technology, Universiti Teknologi Malaysia, 51400 Kuala Lumpur, Malaysia; Advanced Devices Lab, MIMOS Berhad, 57000 Kuala Lumpur, Malaysia

Mohd Ismahadi Syono - Advanced Devices Lab, MIMOS Berhad, 57000 Kuala Lumpur, Malaysia

Mohd Ambri Mohamed - Institute of Microengineering and Nanoelectronics, Universiti Kebangsaan Malaysia, 43600 Bangi, Malaysia

Azrul Azlan Hamzah - Institute of Microengineering and Nanoelectronics, Universiti Kebangsaan Malaysia, 43600 Bangi, Malaysia

Complete contact information is available at: https://pubs.acs.org/10.1021/acsomega.1c01520

\section{Author Contributions}

N.H.Z.A. and M.A.S.M.H. contributed equally to this work. N.H.Z.A. and M.A.S.M.H. directed and wrote the main manuscript text. The design, growth, and characterization of $\mathrm{N}$-doped graphene were conducted by N.H.Z.A. M.A.S.M.H., M.I.S., M.A.M., A.A.H., and A.M.H. provided support in the monitoring, verification of the results, and revision of the manuscript. All authors approved the manuscript.

\section{Notes}

The authors declare no competing financial interest.

\section{ACKNOWLEDGMENTS}

This study was funded by the Ministry of Higher Education (MOHE), Malaysia, under the Fundamental Research Grant Scheme (FRGS/1/2020/STG05/UKM/02/9), and Geran Galakan Penyelidik Muda (GGPM-2020-044) from Universiti Kebangsaan Malaysia (UKM), Malaysia. This study was also supported by Malaysia-Japan International Institute of Technology (MJIIT), Universiti Teknologi Malaysia (UTM). Special thanks to Malaysia-Japan International Institute of Technology (MJIIT) for the scholarship and engineers of Wafer FAB \& Material Analysis Lab at MIMOS Berhad, Malaysia for the technical assistance.

\section{REFERENCES}

(1) Geim, A. K.; Novoselov, K. S. The rise of graphene. Nat. Mater. 2007, 6, 183-191.

(2) Schwierz, F. Graphene transistors. Nat. Nanotechnol. 2010, 5, 487-496.

(3) Becerril, H. A.; Mao, J.; Liu, Z.; Stoltenberg, R. M.; Bao, Z.; Chen, $\mathrm{Y}$. Evaluation of solution-processed reduced graphene oxide films as transparent conductors. ACS Nano 2008, 2, 463-470.

(4) Kim, K. S.; Zhao, Y.; Jang, H.; Lee, S. Y.; Kim, J. M.; Kim, K. S.; Ahn, J. H.; Kim, P.; Choi, J. Y.; Hong, B. H. Large-scale pattern growth of graphene films for stretchable transparent electrodes. Nature 2009, 457, 706-710.

(5) Abdullah, M. F.; Hashim, A. M. Improved coverage of rGO film on $\mathrm{Si}$ inverted pyramidal microstructures for enhancing the photovoltaic of $\mathrm{rGO} / \mathrm{Si}$ heterojunction solar cell. Mater. Sci. Semicond. Process. 2019, 96, 137-144.

(6) Mohammad Haniff, M. A. S.; Ariffin, N. H. Z.; Hafiz, S. M.; Ooi, P. C.; Syono, M. I.; Hashim, A. M. Wafer-scale fabrication of nitrogendoped reduced graphene oxide with enhanced quaternary- $\mathrm{N}$ for highperformance photodetection. ACS Appl. Mater. Interfaces 2019, 11, $4625-4636$

(7) Feng, X.; He, Z.; Zhu, W.; Zhao, M.; Liu, Z.; Yang, S.; Tang, S.; Guo, Q.; Jin, Z.; Chen, D.; Ding, G.; Wang, G. Perovskite quantum dots integrated with vertically aligned graphene toward ambipolar multifunctional photodetectors. J. Mater. Chem. C 2021, 9, 609-619.

(8) Zhao, Y.; Feng, X.; Zhao, M.; Zeng, X.; Liu, Z.; Yang, S.; Tang, S.; Chen, D.; Wang, G.; Ding, G. High-performance near-infrared photodetectors based on $\mathrm{C}_{3} \mathrm{~N}$ quantum dots integrated with singlecrystal graphene. J. Mater. Chem. C 2021, 9, 1333-1338.

(9) Shao, Y.; Wang, J.; Wu, H.; Liu, J.; Aksay, I. A.; Lin, Y. Graphene based electrochemical sensors and biosensors: A review. Electroanalysis 2010, 22, 1027-1036.

(10) Zhao, M.; Zhu, W.; Feng, X.; Yang, S.; Liu, Z.; Tang, S.; Chen, D.; Guo, Q.; Wang, G.; Ding, G. Role of interface 2D graphene in high performance 3D graphene/germanium Schottky junction humidity sensors. J. Mater. Chem. C 2020, 8, 14196-14202.

(11) Li, J.; Liu, Z.; Guo, Q.; Yang, S.; Xu, A.; Wang, Z.; Wang, G.; Wang, Y.; Chen, D.; Ding, G. Controllable growth of vertically oriented graphene for high sensitivity gas detection. J. Mater. Chem. C 2019, 7, 5995-6003.

(12) Novoselov, K. S.; Geim, A. K.; Morozov, S. V.; Jiang, D.; Zhang, Y.; Dubonos, S. V.; Grigorieva, I. V.; Firsov, A. A. Electric field effect in atomically thin carbon films. Science 2004, 306, 666-669.

(13) Berger, C.; Song, Z.; Li, X.; Wu, X.; Brown, N.; Naud, C.; Mayou, D.; Li, T.; Hass, J.; Marchenkov, A. N.; Conrad, E. H.; First, P. N.; de Heer, W. A. Electronic confinement and coherence in patterned epitaxial graphene. Science 2006, 312, 1191-1196.

(14) Guo, B.; Fang, L.; Zhang, B.; Gong, J. R. Graphene doping: A review. Insci. J. 2011, 1, 80-89.

(15) Lee, H.; Paeng, K.; Kim, I. S. A review of doping modulation in graphene. Synth. Met. 2018, 244, 36-47.

(16) Geng, D.; Yang, S.; Zhang, Y.; Yang, J.; Liu, J.; Li, R.; Sham, T. K.; Sun, X.; Ye, S.; Knights, S. Nitrogen doping effects on the structure of graphene. Appl. Surf. Sci. 2011, 257, 9193-9198.

(17) Wang, H.; Maiyalagan, T.; Wang, X. Review on recent progress in nitrogen-doped graphene: Synthesis, characterization, and its potential applications. ACS Catal. 2012, 2, 781-794.

(18) Matter, P. H.; Zhang, L.; Ozkan, U. S. The role of nanostructure in nitrogen-containing carbon catalyst for the oxygen reduction reaction. J. Catal. 2006, 239, 83-96.

(19) Wei, D.; Liu, Y.; Wang, Y.; Zhang, H.; Huang, L.; Yu, G. Synthesis of $\mathrm{N}$-doped graphene by chemical vapor deposition and its electrical properties. Nano Lett. 2009, 9, 1752-1758.

(20) Luo, Z.; Lim, S.; Tian, Z.; Shang, J.; Lai, L.; MacDonald, B.; Fu, C.; Shen, Z.; Yu, T.; Lin, J. Pyridinic N doped graphene: Synthesis, electronic structure, and electrocatalytic property. J. Mater. Chem. 2011, 21, 8038-8044.

(21) Sui, Y.; Zhu, B.; Zhang, H.; Shu, H.; Chen, Z.; Zhang, Y.; Zhang, Y.; Wang, B.; Tang, C.; Xie, X.; Yu, G.; Jin, Z.; Liu, X. 
Temperature-dependent nitrogen configuration of $\mathrm{N}$-doped graphene by chemical vapor deposition. Carbon 2015, 81, 814-820.

(22) Jin, Z.; Yao, J.; Kittrell, C.; Tour, J. M. Large-scale growth and characterizations of nitrogen-doped monolayer graphene sheets. ACS Nano 2011, 5, 4112-4117.

(23) Zabet-Khosousi, A.; Zhao, L.; Pálová, L.; Hybertsen, M. S.; Reichman, D. R.; Pasupathy, A. N.; Flynn, G. W. Segregation of sublattice domains in nitrogen-doped graphene. J. Am. Chem. Soc. 2014, 136, 1391-1397.

(24) Weatherup, R. S.; Bayer, B. C.; Blume, R.; Ducati, C.; Baehtz, C.; Schlogl, R.; Hofmann, S. In situ characterization of alloy catalyst for low temperature graphene growth. Nano Lett. 2011, 11, 41544160.

(25) Mohammad Haniff, M. A. S.; Ariffin, N. H. Z.; Ooi, P. C.; Razip Wee, M. F. M. R.; Mohamed, M. A.; Hamzah, A. A.; Syono, M. I.; Hashim, A. M. Practical route for the low-temperature growth of large-area bilayer graphene on polycrystalline nickel by cold-wall chemical vapor deposition. ACS Omega 2021, 6, 12143-12154.

(26) Terasawa, T.; Saiki, K. Synthesis of nitrogen-doped graphene by plasma-enhanced chemical vapor deposition. Jpn. J. Appl. Phys. 2012, 51, No. 055101.

(27) Wang, C.; Zhao, Y.; He, L.; Ng, T. W.; Hong, G.; Wu, Q. H.; Gao, F.; Lee, C. S.; Zhang, W. In situ nitrogen doped graphene grown from polydimethylsiloxane by plasma enhanced chemical vapor deposition. Nanoscale 2013, 5, 600-605.

(28) Wei, D.; Peng, L.; Li, M.; Mao, H.; Niu, T.; Han, C.; Chen, W.; Wee, A. T. S. Low temperature critical growth of high quality nitrogen doped graphene on dielectrics by plasma-enhanced chemical vapor deposition. ACS Nano 2015, 9, 164-171.

(29) Boas, C. R. S. V.; Focassio, B.; Marinho, E., Jr.; Larrude, D. G.; Salvadori, M. C.; Leao, C. R.; dos Santos, D. J. Characterization of nitrogen doped graphene bilayers synthesized by fast, low temperature microwave plasma-enhanced chemical vapour deposition. Sci. Rep. 2019, 9, No. 13715.

(30) Zhang, J.; Li, J.; Wang, Z.; Wang, X.; Feng, W.; Zheng, W.; $\mathrm{Cao}, \mathrm{W}$.; $\mathrm{Hu}, \mathrm{P}$. Low temperature growth of large- area heteroatomdoped graphene film. Chem. Mater. 2014, 26, 2460-2466.

(31) Xue, Y.; Wu, B.; Jiang, L.; Guo, L.; Huang, I.; Chen, J.; Tan, J.; Geng, D.; Luo, B.; Hu, W.; Yu, G.; Liu, Y. Low temperature growth of highly nitrogen-doped single crystal graphene arrays by chemical vapor deposition continuous graphene films from benzene by chemical vapor deposition. J. Am. Chem. Soc. 2012, 134, 1106011063.

(32) Son, M.; Chee, S.-S.; Kim, S.-Y.; Lee, W.; Kim, Y. H.; Oh, B.-Y.; Hwang, J. Y.; Lee, B. H.; Ham, M.-H. High-quality nitrogen-doped graphene films synthesized from pyridine via two-step chemical vapor deposition. Carbon 2020, 159, 579-585.

(33) Jang, J.; Son, M.; Chung, S.; Kim, K.; Cho, C.; Lee, B. H.; Ham, M.-H. Low-temperature-grown continuous graphene films from benzene by chemical vapor deposition at ambient pressure. Sci. Rep. 2015, 5, No. 17955.

(34) Li, X. S.; Cai, W. W.; An, J. H.; Kim, S.; Nah, K.; Yang, D. X.; Piner, R.; Velamakanni, A.; Jung, I.; Tutuc, E.; Banerjee, S. K.; Colombo, L.; Ruoff, R. S. Large-area synthesis of high-quality and uniform graphene films on copper foils. Science 2009, 324, 13121314.

(35) McNerny, D. Q.; Viswanath, B.; Copic, D.; Laye, F. R.; Prohoda, C.; Brieland-Shoultz, A. C.; Polsen, E. S.; Dee, N. T.; Veerasamy, V. S.; Hart, A. J. Direct fabrication of graphene on $\mathrm{SiO}_{2}$ enabled by thin film stress engineering. Sci. Rep. 2015, 4, No. 5049.

(36) Nair, R. R.; Blake, P.; Grigorenko, A. N.; Novoselov, K. S.; Booth, T. J.; Stauber, T.; Peres, N. M. R.; Geim, A. K. Fine structure constant defines visual transparency of graphene. Science 2008, 320, 1308.

(37) Capasso, A.; Dikonimos, T.; Sarto, F.; Tamburrano, A.; De Bellis, G.; Sarto, M. S.; Faggio, G.; Malara, A.; Messina, G.; Lisi, N. Nitrogen-doped graphene films from chemical vapor deposition of pyridine: Influence of process parameters on the electrical and optical properties. Beilstein J. Nanotechnol. 2015, 6, 2028-2038.
(38) Sun, J.; Chen, Y.; Cai, X.; Ma, B.; Chen, Z.; Priydarshi, M. K.; Chen, K.; Gao, T.; Song, X.; Ji, Q.; Guo, X.; Zou, D.; Zhang, Y.; Lui, $\mathrm{Z}$. Direct low-temperature synthesis of graphene on various glasses by plasma-enhanced chemical vapor deposition for versatile, costeffective electrodes. Nano Res. 2015, 8, 3496-3504.

(39) Weber, N.-E.; Binder, A.; Kettner, M.; Hirth, S.; Weitz, R. T.; Tomović, Ž. Metal-free synthesis of nanocrystalline graphene on insulating substrates by carbon dioxide-assisted chemical vapor deposition. Carbon 2017, 112, 201-207.

(40) Muñoz, R.; Munuera, C.; Martínez, J. I.; Azpeitia, J.; GómezAleixandre, C.; García-Hernández, M. Low temperature metal free growth of graphene on insulating substrates by plasma assisted chemical vapor deposition. 2D Mater. 2017, 4, No. 015009.

(41) Haniff, M. A. S. M.; Hafiz, S. M.; Huang, N. M.; Rahmah, S. A.; Wahid, K. A. A.; Syono, M. I.; Azid, I. A. Piezoresistive effect in plasma-doping of graphene sheet for high-performance flexible pressure sensing application. ACS Appl. Mater. Interfaces 2017, 9, $15192-15201$.

(42) Lu, Y.-F.; Lo, S.-T.; Lin, J.-C.; Zhang, W.; Lu, J.-Y.; Liu, F.-H.; Tseng, C.-H.; Lee, Y.-H.; Liang, C.-T.; Li, L.-J. Nitrogen-doped graphene sheets grown by chemical vapor deposition: Synthesis and influence of nitrogen impurities on carrier transport. ACS Nano 2013, 7, 6522-6532.

(43) Koós, A. A.; Murdock, A. T.; Nemes-Icnze, P.; Nicholls, R. J.; Pollard, A. J.; Spencer, S. J.; Shard, A. G.; Roy, D.; Biró, L. P.; Grobert, N. Effects of temperature and ammonia flow rate on the chemical vapour deposition growth of nitrogen-doped graphene. Phys. Chem. Chem. Phys. 2014, 16, 19446-19452.

(44) Zhang, J.; Zhao, C.; Liu, N.; Zhang, H.; Liu, J.; Fu, Y. Q.; Guo, B.; Wang, Z.; Lei, S.; Hu, P. Tunable electronic properties of graphene through controlling bonding configurations of doped nitrogen atoms. Sci. Rep. 2016, 6, No. 28330.

(45) Wang, L.; Yi, Y.; Zhao, Y.; Zhang, R.; Zhang, J.; Guo, H. $\mathrm{NH}_{3}$ decomposition for $\mathrm{H}_{2}$ generation: Effects of cheap metals and supports on plasma-catalyst synergy. ACS Catal. 2015, 5, 4167-4174.

(46) Wei, D.; Lu, Y.; Han, C.; Niu, T.; Chen, W.; Wee, A. T. S. Critical crystal growth of graphene on dielectric substrates at low temperature for electronic devices. Angew. Chem., Int. Ed. 2013, 52, 14121-14126.

(47) Gan, X.; Zhou, H.; Zhu, B.; Yu, X.; Jia, Y.; Sun, B.; Zhang, M.; Huang, X.; Liu, J.; Luo, T. A simple method to synthesize graphene at $633 \mathrm{k}$ by dechlorination of hexachlorobenzene on cu foils. Carbon 2012, 50, 306-310.

(48) Zheng, S.; Zhong, G.; Wu, X.; D’Arsiè, L.; Robertson, J. Metalcatalyst-free growth of graphene on insulating substrates by ammoniaassisted microwave plasma-enhanced chemical vapor deposition. RSC Adv. 2017, 7, 33185-33193.

(49) Zhang, C.; Fu, L.; Liu, N.; Liu, M.; Wang, Y.; Liu, Z. Synthesis of nitrogen-doped graphene using embedded carbon and nitrogen sources. Adv. Mater. 2011, 23, 1020-1024.

(50) Venezuela, P.; Lazzeri, M.; Mauri, F. Theory of double-resonant raman spectra in graphene: Intensity and line shape of defect-induced and two-phonon bands. Phys. Rev. B 2011, 84, No. 035433.

(51) Casiraghi, C.; Hartschuh, A.; Qian, H.; Piscanec, S.; Georgi, C.; Fasoli, A.; Novoselov, K. S.; Basko, D. M.; Ferrari, A. Raman spectroscopy of graphene edges. Nano Lett. 2009, 9, 1433-1441.

(52) Cuong, N. K.; Tahara, M.; Yamauchi, N.; Sone, T. Diamondlike carbon films deposited on polymers by plasma-enhanced chemical vapor deposition. Surf. Coat. Technol. 2003, 174-175, 1024-1028.

(53) Das, A.; Pisana, S.; Chakraborty, B.; Picsanec, S.; Saha, S. K.; Waghmare, U. V.; Novoselov, K. S.; Krishnamurthy, H. R.; Geim, A. K.; Ferrari, A. C.; Sood, A. K. Monitoring dopants by raman scattering in an electrochemically top-gated graphene transistor. Nat. Nanotechnol. 2008, 3, 210-215.

(54) Deng, D.; Pan, X.; Yu, L.; Cui, Y.; Jiang, Y.; Qi, J.; Li, W.-X.; Fu, Q.; Ma, X.; Xue, Q.; Sun, G.; Bao, X. Toward N-doped graphene via solvothermal synthesis. Chem. Mater. 2011, 23, 1188-1193.

(55) Cançado, L. G.; Jorio, A.; Martins Ferreira, E. H.; Stavale, F.; Achete, C. A.; Capaz, R. B.; Moutinho, M. V. O.; Lambardo, A.; 
Kulmala, T. S.; Ferrari, A. C. Quantifying defects in graphene via raman spectroscopy at different excitation energies. Nano Lett. 2011, 11, 3190-3196.

(56) Jin, Z.; Yao, J.; Kittrel, C.; Tour, J. M. Large-scale growth and characterizations of nitrogen-doped monolayer graphene sheets. ACS Nano 2011, 5, 4112.

(57) Tuinstra, F.; Koenig, J. L. Raman spectrum of graphite. J. Chem. Phys. 1970, 53, 1126.

(58) He, B.; Ren, Z.; Qi, C.; Yan, S.; Wang, Z. Synthesis of nitrogendoped monolayer graphene with high transparent and n-type electrical properties. J. Mater. Chem. C 2015, 3, 6172-6177.

(59) Hofer, C.; Skákalová, V.; Görlich, T.; Tripathi, M.; Mittelberger, A.; Mangler, C.; Monazam, M. R. A.; Susi, T.; Kotakoski, J.; Meyer, J. C. Direct imaging of light-element impurities in graphene reveals triple-coordinated oxygen. Nat. Commun. 2019, 10, No. 4570.

(60) Yuk, J. M.; Park, J.; Ercius, P.; Kim, K.; Hellebusch, D. J.; Crommie, M. F.; Lee, J. Y.; Zettl, A.; Alivisatos, A. P. High-resolution EM of colloidal nanocrystal growth using graphene liquid cells. Science 2012, 336, 61-64.

(61) Meyer, J. C.; Kurasch, S.; Park, H. J.; Skakalova, V.; Künzel, D.; Groß, A.; Chuvilin, A.; Algara-Siller, G.; Roth, S.; Iwasaki, T.; Starke, U.; Smet, J. H.; Kaiser, U. Experimental analysis of charge redistribution due to chemical bonding by high-resolution transmission electron microscopy. Nat. Mater. 2011, 10, 209-215.

(62) Snow, E. S.; Novak, J. P.; Campbell, P. M.; Park, D. Random networks of carbon nanotubes as an electronic material. Appl. Phys. Lett. 2003, 82, 2145. 